\title{
New emission factors for Australian vegetation fires measured using open-path Fourier transform infrared spectroscopy - Part 2: Australian tropical savanna fires
}

\author{
T. E. L. Smith ${ }^{1}$, C. Paton-Walsh ${ }^{2}$, C. P. Meyer ${ }^{3}$, G. D. Cook $^{4}$, S. W. Maier ${ }^{5}$, J. Russell-Smith ${ }^{5}$, M. J. Wooster ${ }^{1}$, and \\ C. P. Yates ${ }^{5}$ \\ ${ }^{1}$ King's College London, Earth and Environmental Dynamics Research Group, Department of Geography, London, UK \\ ${ }^{2}$ Centre for Atmospheric Chemistry, School of Chemistry, University of Wollongong, Wollongong, \\ New South Wales, Australia \\ ${ }^{3}$ CSIRO Marine and Atmospheric Sciences, PMB 1, Aspendale, Victoria, Australia \\ ${ }^{4}$ CSIRO Ecosystem Sciences Sustainable Agriculture Flagship, PMB 44, Winnellie, Northern Territory, Australia \\ ${ }^{5}$ Charles Darwin University, Research Institute for the Environment and Livelihoods, Darwin, Northern Territory, Australia
}

Correspondence to: T. E. L. Smith (thomas.smith@kcl.ac.uk)

Received: 30 December 2013 - Published in Atmos. Chem. Phys. Discuss.: 11 March 2014

Revised: 16 September 2014 - Accepted: 17 September 2014 - Published: 29 October 2014

\begin{abstract}
Savanna fires contribute approximately 40-50\% of total global annual biomass burning carbon emissions. Recent comparisons of emission factors from different savanna regions have highlighted the need for a regional approach to emission factor development, and better assessment of the drivers of the temporal and spatial variation in emission factors. This paper describes the results of open-path Fourier transform infrared (OP-FTIR) spectroscopic field measurements at 21 fires occurring in the tropical savannas of the Northern Territory, Australia, within different vegetation assemblages and at different stages of the dry season. Spectra of infrared light passing through a long $(22-70 \mathrm{~m})$ openpath through ground-level smoke released from these fires were collected using an infrared lamp and a field-portable FTIR system. The IR spectra were used to retrieve the mole fractions of 14 different gases present within the smoke, and these measurements used to calculate the emission ratios and emission factors of the various gases emitted by the burning. Only a handful of previous emission factor measures are available specifically for the tropical savannas of Australia and here we present the first reported emission factors for methanol, acetic acid, and formic acid for this biome. Given the relatively large sample size, it was possible to study the potential causes of the within-biome variation of the derived emission factors. We find that the emission factors vary sub-
\end{abstract}

stantially between different savanna vegetation assemblages; with a majority of this variation being mirrored by variations in the modified combustion efficiency (MCE) of different vegetation classes. We conclude that a significant majority of the variation in the emission factor for trace gases can be explained by MCE, irrespective of vegetation class, as illustrated by variations in the calculated methane emission factor for different vegetation classes using data sub-set by different combustion efficiencies. Therefore, the selection of emission factors for emissions modelling purposes need not necessarily require detailed fuel type information, if data on MCE (e.g. from future spaceborne total column measurements) or a correlated variable were available.

From measurements at 21 fires, we recommend the following emission factors for Australian tropical savanna fires (in grams of gas emitted per kilogram of dry fuel burned), which are our mean measured values: $1674 \pm 56 \mathrm{~g} \mathrm{~kg}^{-1}$ of carbon dioxide; $87 \pm 33 \mathrm{~g} \mathrm{~kg}^{-1}$ of carbon monoxide; $2.1 \pm 1.2 \mathrm{~g} \mathrm{~kg}^{-1}$ of methane; $0.11 \pm 0.04 \mathrm{~g} \mathrm{~kg}^{-1}$ of acetylene; $0.49 \pm 0.22 \mathrm{~g} \mathrm{~kg}^{-1}$ of ethylene; $0.08 \pm 0.05 \mathrm{~g} \mathrm{~kg}^{-1}$ of ethane; $1.57 \pm 0.44 \mathrm{~g} \mathrm{~kg}^{-1}$ of formaldehyde; $\quad 1.06 \pm 0.87 \mathrm{~g} \mathrm{~kg}^{-1}$ of methanol; $1.54 \pm 0.64 \mathrm{~g} \mathrm{~kg}^{-1}$ of acetic acid; $0.16 \pm 0.07 \mathrm{~g} \mathrm{~kg}^{-1}$ of formic acid; $0.53 \pm 0.31 \mathrm{~g} \mathrm{~kg}^{-1}$ of hydrogen cyanide; and $0.70 \pm 0.36 \mathrm{~g} \mathrm{~kg}^{-1}$ of ammonia. In a companion paper, 
similar techniques are used to characterise the emissions from Australian temperate forest fires.

\section{Introduction}

Estimates of mean annual carbon emissions from worldwide savanna and grassland fires amount to $\sim 1 \mathrm{PgC}$ per year (2000-2009), or approximately a mean of $40-50 \%$ of total global annual biomass burning carbon emissions (van der Werf et al., 2010). In terms of the Australian savanna, the direct gross carbon emissions from fires have a similar, if not greater, magnitude than those from Australian fossil fuel combustion (Haverd et al., 2013). However, in tropical Australia, net carbon emissions from fires are considered negligible as the carbon lost to burning is approximately balanced by the carbon sequestered during regrowth (Haverd et al., 2013). Akagi et al. (2011) present summaries of emission factors (EFs) that can be used to convert estimates of total biomass (or carbon) consumed in fires into estimates of individual trace gas species release. Emissions of non- $\mathrm{CO}_{2}$ gases from savanna fires, such as nitrous oxide and methane, whose emissions are not sequestered by regrowth, comprise $2-4 \%$ of total Australian national greenhouse gas emissions (DCCEE, 2010), and are included in the accountable greenhouse gas inventory. At state or territory scales, pyrogenic emissions of $\mathrm{CO}_{2}, \mathrm{CH}_{4}$, and $\mathrm{N}_{2} \mathrm{O}$ can be far more significant, with emissions from fires comprising nearly $50 \%$ of the Northern Territory's accountable carbon emissions (DCCEE, 2010).

A clear understanding of the emissions characteristics of Australia's tropical savannas is important for regional emissions modelling and for associated greenhouse gas accounting schemes. As with the fire regimes of other savanna regions, that in Australia's tropical savanna is heavily influenced by human fire use and fire management (Garde, 2009; Cook et al., 2010). Currently, policy in the Northern Territory of Australia aims to reduce overall savanna fire emissions by promoting early dry-season (pre mid-July) fires which consume less fuel and create a network of fire breaks that reduce the extent of late dry-season (post mid-July) fires, reducing overall fire frequency (Cook and Meyer, 2009; Russell-Smith et al., 2009). Given that the seasonality of the emission factor for methane in Australian tropical savannas has recently been shown to be different to that observed in African savannahs (Meyer et al., 2012), it is evidently important to make regionally specific measurements of emission factors so that the most accurate assessments of the effectiveness of such policies, and the impact of fire management on greenhouse gas and reactive gas emissions, can be provided.

Despite the prevalence of savanna fires on the Australian continent, with approximately $400000 \mathrm{~km}^{2}$ of tropical savannas ( $\sim 15 \%$ of global tropical savannas) and $150000 \mathrm{~km}^{2}$ of arid savannas burning annually (Russell-Smith et al., 2007; Meyer et al., 2012), the focus of most savanna emissions re- search has been on Africa (e.g. Bertschi et al., 2003a; Yokelson et al., 2003; Sinha et al., 2003; Keane et al., 2006). Only Hurst et al. (1994a, b), and Shirai et al. (2003) have published emission factors from Australian savannas, with most measurements made using airborne campaigns. Most recently, Meyer et al. (2012) have published emission factors for methane $\left(\mathrm{CH}_{4}\right)$ and nitrous oxide $\left(\mathrm{N}_{2} \mathrm{O}\right)$ from Australian savannas using ground-based sampling methods.

Careful interpretation of data collected from these various methods is required to ensure the accurate characterisation of fire-averaged emissions (Akagi et al., 2011). Beyond these methodological complications are the factors that lead to the natural variability of emissions (e.g. interactions between meteorology, seasonality and combustion efficiency). As the recent study by van Leeuwen and van der Werf (2011) shows, within-biome temporal and spatial variations in emission factors are substantial, and despite their attempts to explain these using relationships between emission factors and a number of environmental variables (tree cover density, vegetation greenness, temperature, precipitation, length of dry season), correlations between $\mathrm{CO}, \mathrm{CH}_{4}$ and $\mathrm{CO}_{2} \mathrm{EFs}$, and modified combustion efficiency (MCE), were rather low, with environmental variables explaining $33,38,19$, and $34 \%$ of the variation in the reported emissions metrics, respectively. Van Leeuwen and van der Werf (2011) posit some potential reasons for the poor explanation of within-biome variability, including different measurement techniques for EFs, assumptions used to weight EFs by the amount of flaming and smouldering combustion and uncertainties in the environmental variables themselves. Explaining the large natural variability of EFs that is so pronounced in the findings of Akagi et al. (2011) remains an important challenge for biomass burning emissions science.

Through measurements of a large number of fires during multiple campaigns at different stages of tropical Australia's dry season, this work aims to expand the current emission factors inventory for Australian savannas, whilst also exploring the nature and causes of the natural variability of fire emissions within this ecosystem. Long open-path Fourier transform infrared (OP-FTIR) spectroscopy was used for field measurements of trace gases emitted from 21 different experimental fires or wildfires in the tropical savanna of the Northern Territory, Australia. A thorough discussion of the methodology and emission factors for Australian temperate forest fires can be found in our partner paper, Paton-Walsh et al. (2014)

\section{Methods}

\subsection{The open-path FTIR system and deployment}

FTIR systems can simultaneously record infrared spectra at a high enough spectral resolution and across a wide wavenumber range, such that estimates of the path-averaged mole 
fraction of many of the trace gases present in the path can be retrieved via spectral analysis. The OP-FTIR system operated by King's College London consists of a MIDAC Corporation M2000 Series FTIR spectrometer $\left(0.5 \mathrm{~cm}^{-1}\right.$ resolution) equipped with a Stirling-cycle cooled mercurycadmium-telluride (MCT) detector, and fitted with a MIDAC custom-built $76 \mathrm{~mm}$ Newtonian telescope. Unlike the monostatic pre-modulated source system used by Paton-Walsh et al. (2014), the MIDAC system employed here operates using a bi-static configuration, where the FTIR spectrometer is operated in "active" mode, viewing a remotely located infrared source. Here, the infrared source consists of a $12 \mathrm{~V}$ silicon carbide glowbar operating at $1500 \mathrm{~K}$ fitted in front of a $20 \mathrm{~cm}$ diameter gold-plated aluminium collimator. With a maximum optical path distance of $2 \mathrm{~cm}$, each scan of the spectrometer mirror takes $\sim 1.2 \mathrm{~s}$. To improve the signal-tonoise ratio, it is advantageous to average (co-add) a number of spectral measurements prior to analysis. The MIDAC system and its use to characterise biomass burning emissions via long OP-FTIR spectroscopy is detailed in Wooster et al. (2011), whilst an accuracy assessment with respect to the retrieval of greenhouse gas mole fractions from the collected spectra was undertaken by Smith et al. (2011).

A mixture of purposely lit "experimental" plots and wildfires were studied. At most plots, the OP-FTIR path was positioned on a road, track, or fire-break downwind of the fire plot with pathlengths ranging from 22 to $70 \mathrm{~m}$ (Table 1). There were, however, some exceptions. For some plots, where there was no safe location downwind of the fire plot, the OP-FTIR path was positioned over the plot, with smoke passing between the spectrometer and IR source before or after the fire front passed through this path. Spectra collected during the time in which the fire was burning within the open path were affected by infrared emission from the flames; this effect precludes the retrieval of gas mole fractions from spectra due to the superposition of emission and absorption lines in the spectral signatures (one disadvantage of the bi-static OPFTIR configuration). Consequently, all spectra affected by thermal emission from hot flames were removed prior to the analysis stage. For other plots, and especially for the wildfire measurements, it was not possible to position a path beside or across the fire plot. In these situations, either the IR source, or both the spectrometer and the IR source, were positioned within the fire plot. To protect the equipment from the fire, the equipment was positioned within natural firebreaks (rocky outcrops, areas of low biomass) or artificial firebreaks (raked vegetation) with the OP-FTIR path penetrating into the fire plot, or being entirely enclosed by the fire plot (Fig. 1).

For the experimental plots, it was possible to assemble the OP-FTIR equipment prior to each fire. Burn-offs and wildfires, by their nature, are unpredictable; identification of a position for the OP-FTIR path and assembly of the equipment took place whilst the fire was burning upwind. In one case (at the Adelaide River Station), it was pos-

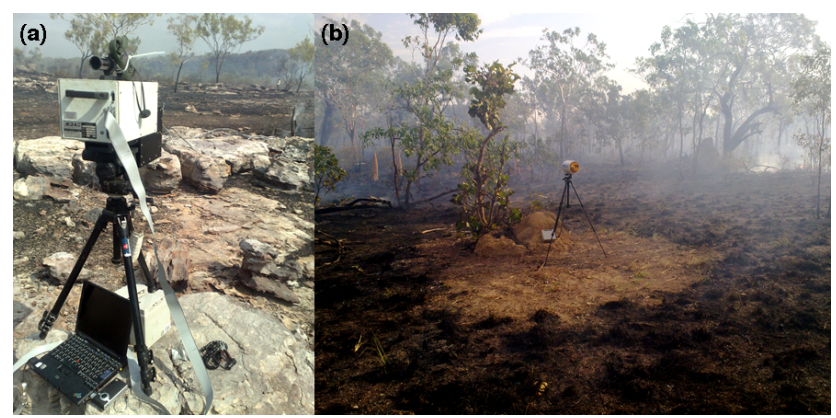

Figure 1. Photographs showing the use of natural and artificial firebreaks to protect the OP-FTIR equipment during fires in which the open path between the spectrometer and IR source lay within the fire plots. (a) The FTIR spectrometer positioned on a rocky outcrop, with the fire being allowed to pass around the rocks; (b) The IR lamp protected by raked vegetation, notice the distinction between the burnt and unburned area.

sible to follow the fire along a track, assembling and reassembling paths as the fire front passed each path location. Given that most plots were small $(<1 \mathrm{Ha})$ and in some cases burned quickly, spectra were collected using four co-added scans to increase signal-to-noise yet still allow for a high measurement frequency (generating approximately one measured spectrum every $5 \mathrm{~s}$ ). Observations of atmospheric temperature and pressure (parameters required for the trace gas retrieval analysis) were made using a co-located WXT510 weather station (Vaisala Oyj, Helsinki, Finland) at the Arnhem Land campaigns. For the Darwin region campaign, temperature and pressure were taken from a Bureau of Meteorology (Australian Government) weather station in Batchelor (located within $60 \mathrm{~km}$ of all of the burn sites).

\subsection{Quantitative analysis of infrared spectra}

For measurements that use a bi-static approach, where the FTIR spectrometer is used to measure a remote collimated non-modulated IR source, as described here, the measured spectrum includes radiation that has originated from the IR source ( $\left.I_{\text {SOURCE }}\right)$, but also from instrument self-emission and from other ambient temperature sources $\left(I_{\mathrm{AMB}}\right)$ within the field of view of the receiving telescope. At the higher wave-number (shorter wavelength) regions used to retrieve gases such as $\mathrm{CO}_{2}, \mathrm{CO}, \mathrm{CH}_{4}, \mathrm{H}_{2} \mathrm{CO}(2000$ $3100 \mathrm{~cm}^{-1}$, see Fig. 2), the ambient signal contribution is almost non-existent. However, at wave-number regions below $\sim 1500 \mathrm{~cm}^{-1}$, where gases such as $\mathrm{C}_{2} \mathrm{H}_{4}, \mathrm{HCOOH}, \mathrm{CH}_{3} \mathrm{OH}$ and $\mathrm{NH}_{3}$ are retrieved, the contribution from ambient sources becomes more important to account for. This ambient signal component introduces a zero-baseline offset to the measured spectra which needs to be removed prior to any trace gas retrieval as this component contains no information related to trace gas absorption (Müller et al., 1999). When $I_{\mathrm{AMB}}$ is small (at wave numbers $>1500 \mathrm{~cm}^{-1}$ ) the effect on measured 
Table 1. List of fires studied using OP-FTIR during the three Northern Territory measurements campaigns in the Arnhem Land and Darwin regions, with information about the plot location, OP-FTIR path length, and meteorological variables.

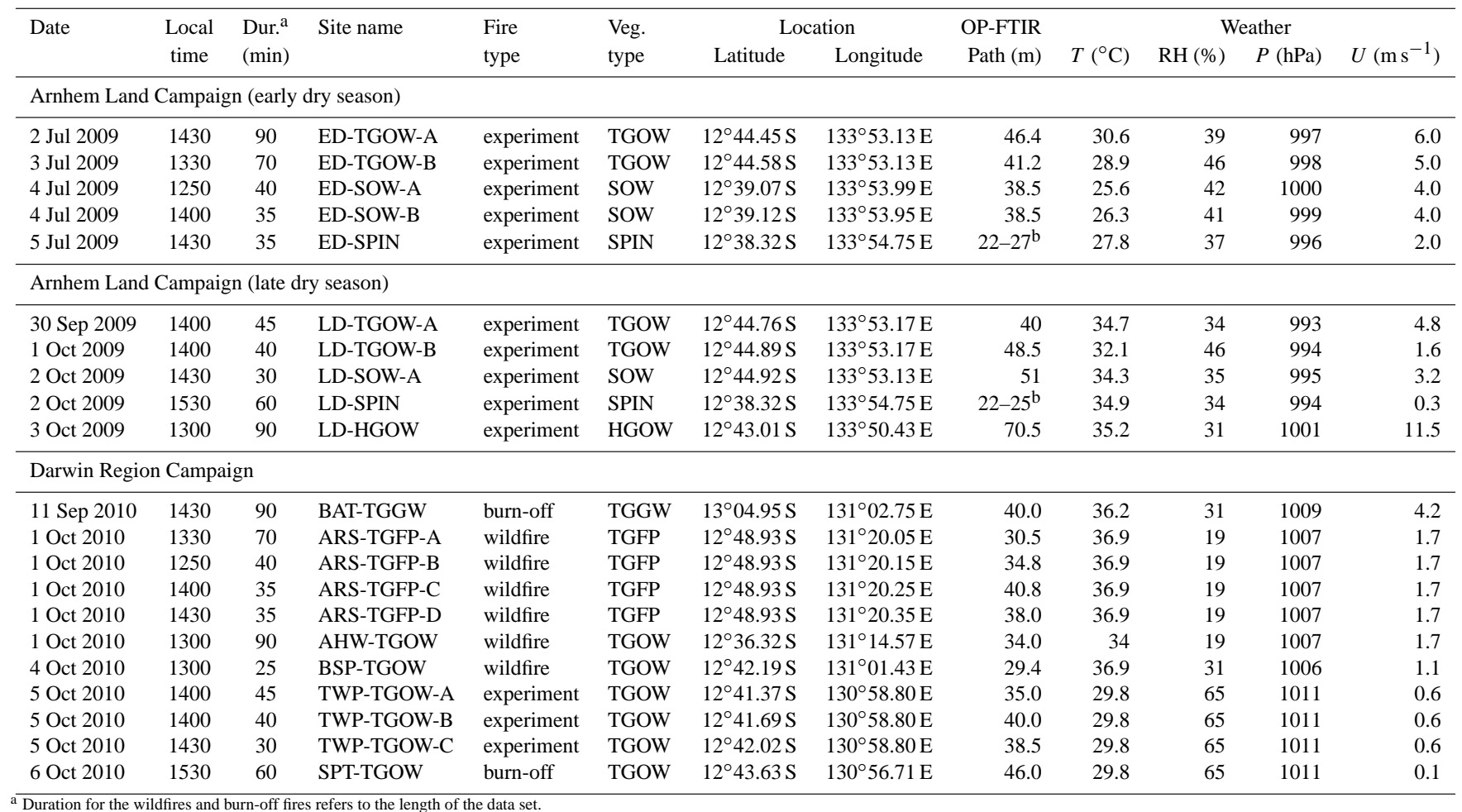

a Duration for the wildfires and burn-off fires refers to the length of the data set.

${ }^{\mathrm{b}}$ Multiple OP-FTIR paths were used for the spinifex fires.

transmittance is relatively minor. However, higher levels of $I_{\mathrm{AMB}}$ at lower wave numbers can significantly alter the apparent transmittance $\left(T_{\text {app }}\right)$ :

$T_{\text {app }}=\frac{I}{I_{\text {SOURCE }}+I_{\mathrm{AMB}}}$.

To correct for this zero-baseline offset, it is necessary to make a measurement of the ambient spectrum (e.g. a spectral measurement with the active IR source turned off) and subtract this spectrum from each measurement of the active IR source, making slight adjustments for any MCT detector non-linearities in accordance with Müller et al. (1999) to ensure that the resultant "difference" spectra exhibit zero signal in saturated spectral regions, such as the $668-670 \mathrm{~cm}^{-1} \mathrm{CO}_{2}$ absorption band (see Fig. 4 in Wooster et al., 2011). Wooster et al. (2011), who follow this methodology, confirm that subtracting the ambient signal has a large effect on retrieved mole fractions of $\mathrm{NH}_{3}$ (retrieved using a spectral window around $\left.940 \mathrm{~cm}^{-1}\right) ; \mathrm{NH}_{3}$ mole fractions increased by a factor of 2 due to the reduced calculated transmittance (through Eq. 1). Wooster et al. (2011) also stress that the impact of ambient signal subtraction is much smaller for retrievals of $\mathrm{CO}_{2}$ and $\mathrm{CO}$ at $\sim 2000 \mathrm{~cm}^{-1}(<10 \%)$. During measurements of a particular fire, some changes in ambient background emission might be expected (e.g. due to changes in air temperature). The majority of measurements presented in this work took place over relatively short-lived fires $(<1 \mathrm{~h})$ and should therefore not be substantially influenced by changes in the ambient background spectrum. Nevertheless, measurements of ambient spectra were made both before and after a fire where possible, to check for any large changes in the ambient spectrum during the course of a fire.

Trace gas mole fractions were retrieved from all open-path FTIR spectra (after subtracting the background spectrum) using the Multiple Atmospheric Layer Transmission (MALT) model, as described in Part 1 of this paper (Paton-Walsh et al., 2014). MALT includes a forward model and a parameter optimisation routine, and has been used previously for retrieving the mole fraction of biomass burning compounds from open-path measurements of smoke in Australia (Griffith et al., 1991; Meyer et al., 2012), and in the United States (Akagi et al., 2014). Working in African savannah, Wooster et al. (2011) used an alternative retrieval code that again used similar physical principles to MALT. A full description of MALT can be found in Griffith (1996).

There are a few differences between the retrieval parameters used here and those used in Part 1 of this paper. Due to the higher spectral resolution of the MIDAC spectrometer, a resolution of $0.5 \mathrm{~cm}^{-1}$ (fixed; $0.96 \mathrm{~cm}^{-1}$ in Part 1) was used here with a field of view of 20 milli-radians (fixed; 22 milli-radians in Part 1); here we apply a triangle apodisation function (Hamming in Part 1). Phase error and 

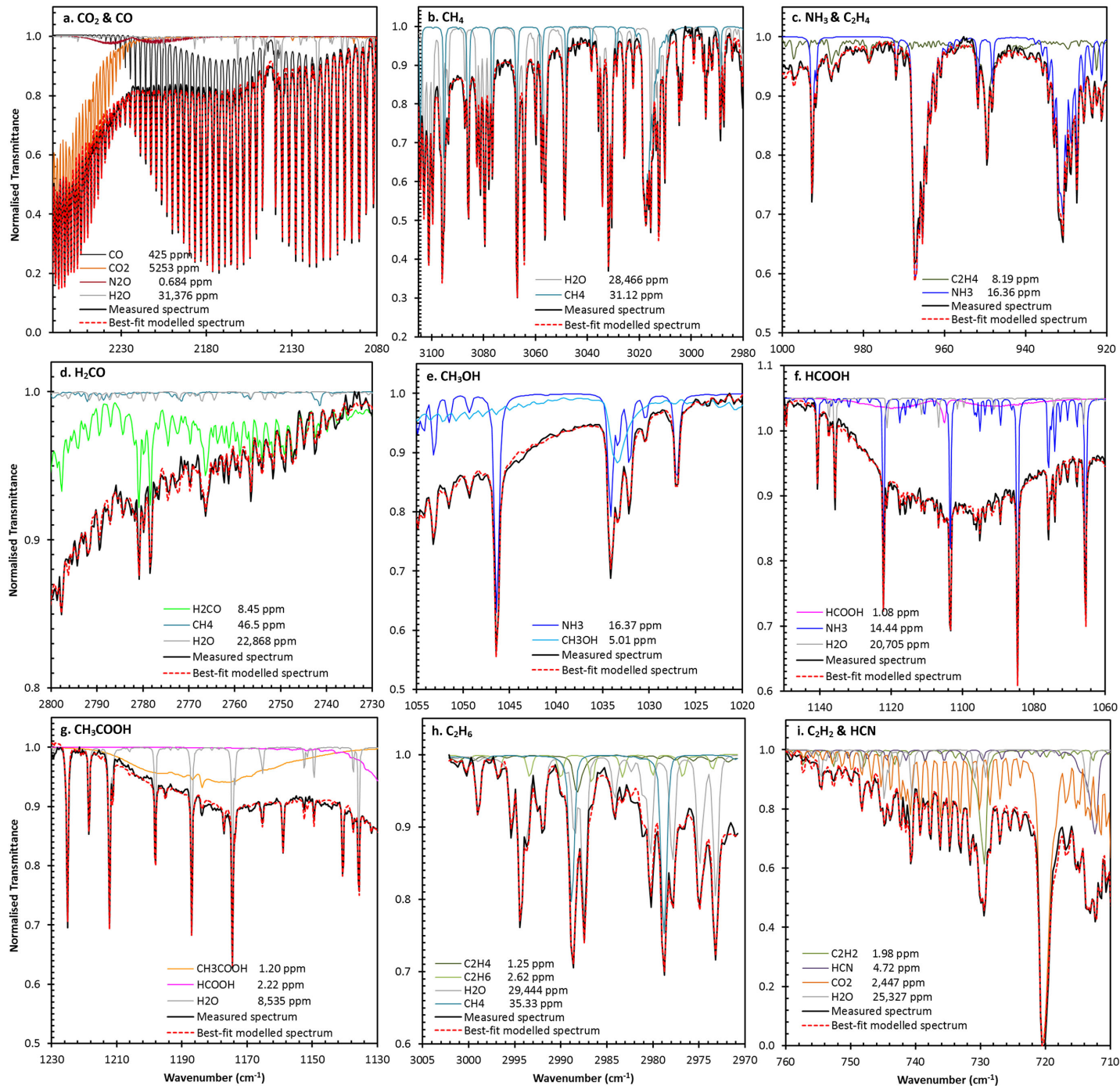

Figure 2. Typical retrieval spectral windows for each of the trace gases retrieved for this paper: (a) $\mathrm{CO}_{2}$ and $\mathrm{CO}_{3}(\mathbf{b}) \mathrm{CH}_{4} ;(\mathbf{c}) \mathrm{C}_{2} \mathrm{H}_{4}$ and $\mathrm{NH}_{3}$; (d) $\mathrm{H}_{2} \mathrm{CO}$; (e) $\mathrm{CH}_{3} \mathrm{OH}$; (f) $\mathrm{HCOOH}$; (g) $\mathrm{CH}_{3} \mathrm{COOH}$; (h) $\mathrm{C}_{2} \mathrm{H}_{6}$; and (i) $\mathrm{C}_{2} \mathrm{H}_{2}$ and $\mathrm{HCN}$. The measured spectrum (black line) and the best-fit modelled spectrum (dashed red line) are shown along with each of the individually modelled trace gas spectra (multiple colours). The modelled spectrum is the sum of each of the individual trace gas spectra convolved to the background polynomial (see Table 1 in Paton-Walsh et al., 2014).

wave-number shifts were fitted in accordance with PatonWalsh et al. (2014).

\subsection{Spectral regions and parameters for quantitative spectral analysis}

A set of standardised spectral windows and retrieval parameters are outlined in Part 1 of this paper (Table 1 in PatonWalsh et al., 2014). The higher spectral resolution and greater wave-number range $\left(700-4000 \mathrm{~cm}^{-1}\right)$ of the MIDAC spectrometer and detector deployed for the measurements presented here allowed for the additional detection of $\mathrm{HCN}$ and $\mathrm{C}_{2} \mathrm{H}_{2}$ in the $710-760 \mathrm{~cm}^{-1}$ region, beyond what was detectable using the spectrometer deployed by Paton-Walsh et al. (2014). A full set of example spectral fits to our $0.5 \mathrm{~cm}^{-1}$ spectra is presented in Fig. 2. Due to the underlying spectral response of the MIDAC spectrometer, a higher-order background polynomial was required for the $\mathrm{HCOOH}$ retrieval window (Fig. 2f); here we use a 3rd-order polynomial, rather than a 2nd-order polynomial as indicated in Table 1 in PatonWalsh et al. (2014).

\subsection{Fire-averaged emission factors and probing natural variability}

Individual fire emission factors were calculated using the method outlined in Part 1 (Paton-Walsh et al., 2014; Sect. 4). Emission factors for $\mathrm{CO}_{2}$ and $\mathrm{CO}$ are calculated via the 


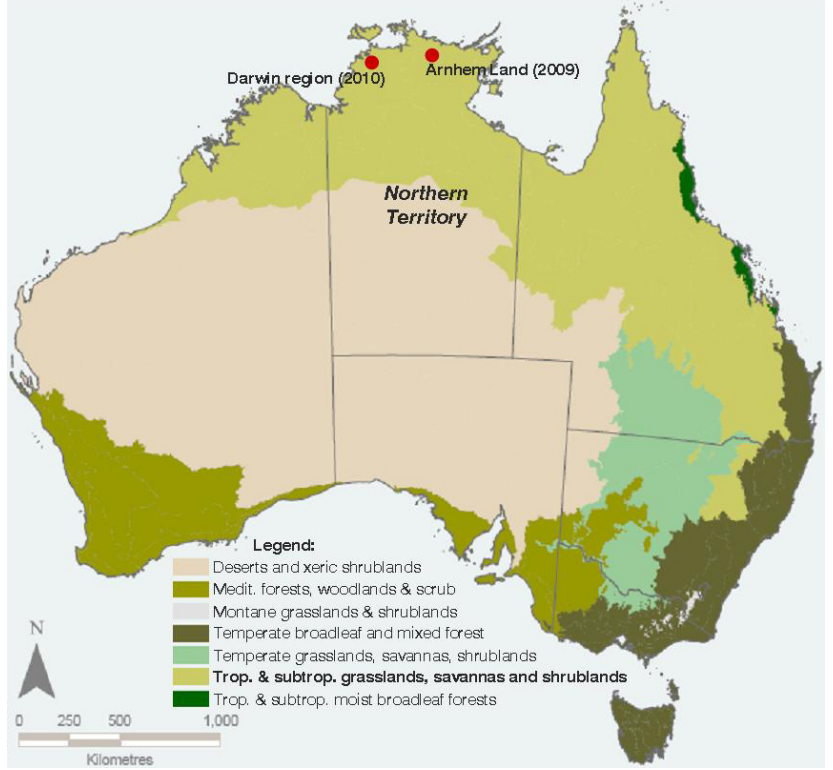

Figure 3. Map of Australia, showing the two field campaign locations. Both the Arnhem Land and Darwin Region campaigns are situated in the "tropical and subtropical grasslands, savannas and shrublands" terrestrial ecoregion (adapted from Parks Australia, 2010).

summation method, using background mole fractions for these gases measured before ignition, or upwind of the fires. Emission factors for the other gases are calculated using their respective emission ratios to either $\mathrm{CO}_{2}$ or $\mathrm{CO}$ as also described in Sect. 4 of Paton-Walsh et al. (2014). Given that the results presented here cover measurements at 21 different fires from distinct tropical savanna ecosystem vegetation assemblages, and measured at different stages of the dry season (Table 1), further analysis will include an assessment of the within-ecosystem variability in emission factors.

\section{Site and fire descriptions}

Savanna fire emissions were measured at experimental fires in July and September 2009 near Kulnguki on the Arnhem Land Plateau, Northern Territory. Further measurements of experimental fires, land management fires and wildfires were carried out during August to October 2010 in the cities of Darwin and Palmerston, Litchfield Municipality, and Coomalie Shire of the Northern Territory. The flora of these areas is typical of eucalyptus-dominated savannas that comprise much of northern Australia, from the Kimberley region of Western Australia, through the Top End of the Northern Territory to Cape York in Queensland (Fig. 3).

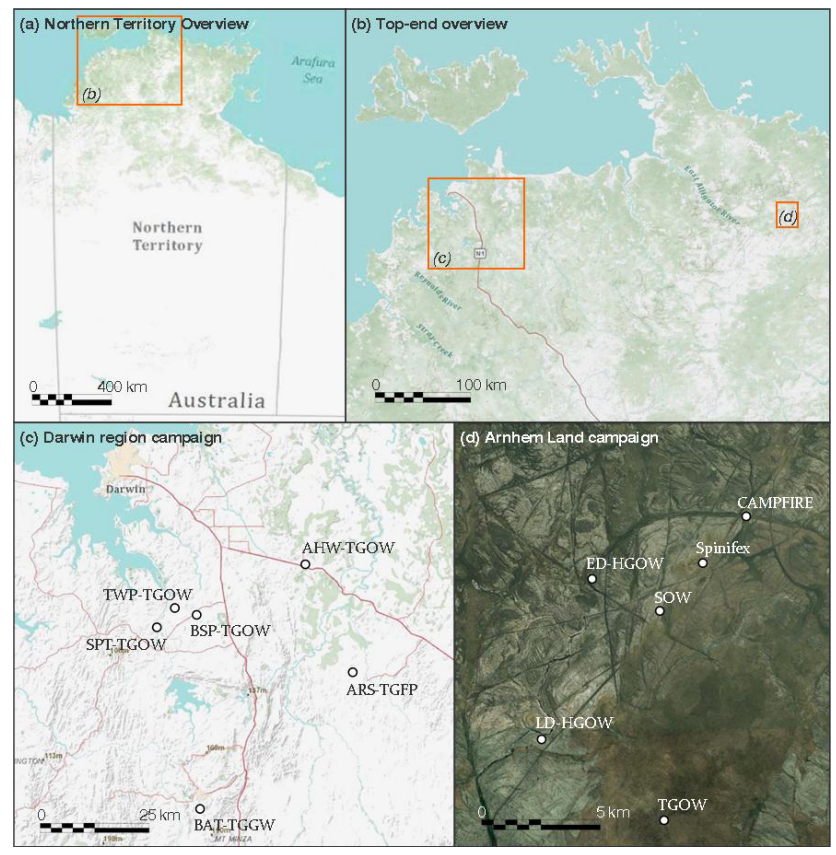

Figure 4. Maps showing the location of each of the fire sites discussed in this paper (see Table 1 for full site descriptions).

\subsection{Arnhem Land}

Measurements in Arnhem Land were conducted during two field campaigns described at length by Meyer et al. (2012). Six experimental fires were measured during the early-dry season (EDS) between 2-7 July 2009, and a further five experimental fires were measured during the late-dry season (LDS) between 30 September and 4 October 2009.

The climate of West Arnhem Land is tropical monsoonal, and $97 \%$ of the mean annual rainfall falls between November and April. The closest weather station, at Oenpelli $\left(12^{\circ} 20^{\prime} \mathrm{S}\right.$ $\left.133^{\circ} 03^{\prime} \mathrm{E}\right), 100 \mathrm{~km}$ west-northwest of the experimental fire sites records a mean annual rainfall of $1417 \mathrm{~mm}$, with a mean maximum temperature of $30^{\circ} \mathrm{C}$ in July and $38^{\circ} \mathrm{C}$ in October.

The experimental fire sites were located near Kulnguki, in West Arnhem Shire, Northern Territory $\left(12^{\circ} 38^{\prime} \mathrm{S} 133^{\circ} 55^{\prime} \mathrm{E}\right.$, Fig. 4), $330 \mathrm{~km}$ east of Darwin. One set of fires were situated on the Queue land system (Lynch and Wilson, 1998; Meyer et al., 2012), a system of sandstone plains dominated by a semi-continuous canopy of Eucalyptus and Corymbia trees, with an Acacia mid-storey (Fig. 5a). The understorey consists of sorghum grasses with a number of shrub species to about 1 metre high. For consistency with Meyer et al. (2012), the vegetation of this system will be referred to as "tussock grass open woodland" (TGOW). Another set of fires were situated on the sandstone plateau of the Buldiva land system (Lynch and Wilson, 1998; Meyer et al., 2012). Here, the dominant trees are similar to that of the TGOW, whereas the understorey is mainly dominated by hummock grass (Triodia) with a variety of shrubs (Fig. 5b). The vegetation of this 


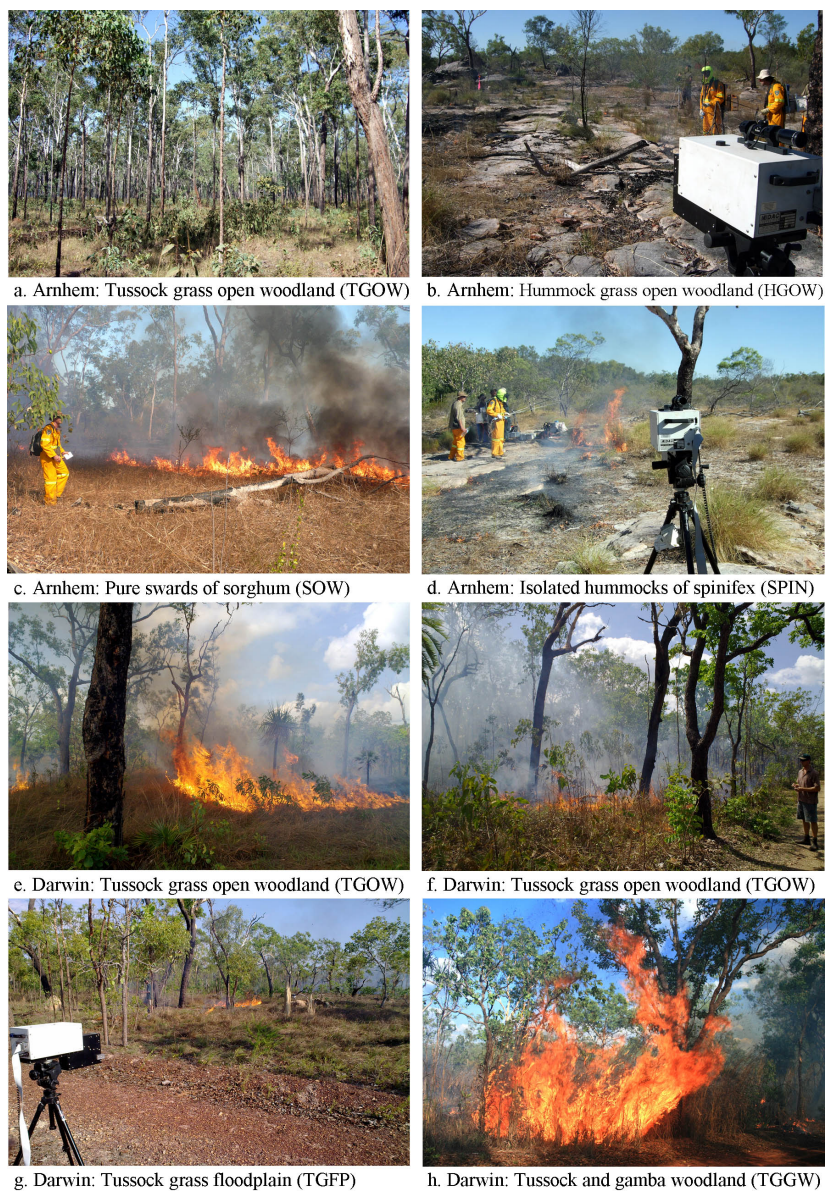

Figure 5. Photographs depicting the various savanna fire classes experienced during both the Arnhem Land (Arnhem) and Darwin region (Darwin) campaigns. The abbreviations in parentheses are used throughout this paper, more details about specific fire plots are given in Table 1.

system will be referred to as "hummock grass open woodland" (HGOW). While tussock grasses can be found in savanna systems worldwide, the hummocky spinifex grasses are endemic to Australia (Meyer et al., 2012), adapted to the arid climate with a shrub-like growth form. In addition to the TGOW and HGOW vegetation classes, fires were measured in open woodland areas with very few trees, dominated by sorghum grasses (Fig. 5c); this vegetation class will be referred to as "sorghum open woodland" (SOW). Individual hummocks of spinifex grasses were also burned and measured for their emissions (Fig. 5d); this vegetation class will be referred to as "pure spinifex" (SPIN). An extended description of the particular species at these fire sites can be found in Meyer et al. (2012).

The tussock-grass open woodland and sorghum open woodland fires were conducted in a series of adjacent plots established prior to the first campaign along an access road. Each tussock-grass open woodland plot was approximately $500 \mathrm{~m} \times 200 \mathrm{~m}$ in size, whilst each sorghum open wood- land plot was approximately $100 \mathrm{~m} \times 100 \mathrm{~m}$ in size. The dissected quartz sandstone landscape of the hummock-grass open woodland allowed for the identification of two isolated plots prior to the campaign, each with areas of 50-70 ha, surrounded by natural fire barriers. The plots were situated in isolated country accessible only by helicopter, approximately $6-10 \mathrm{~km}$ from the tussock-grass plots. These experimental plots were ignited by a line ignition pattern on the upwind side of the plot, with some plots having a back fire also ignited on the downwind side of the plot. The isolated hummocks of spinifex could be ignited individually without risk of establishing a fire front due to the surrounding rocky outcrop. For further descriptions of the Arnhem Land experimental fires, including fuel loads and fuel moisture content, refer to Meyer et al. (2012).

\subsection{Darwin region}

A third measurement campaign to the Northern Territory was conducted during August to October in the dry season of 2010. Measurements were made at a number of wildfires, as well as experimental fires, at various locations within a region $120 \mathrm{~km}$ to the south/southeast of Darwin (Fig. 4). The climate of this area is tropical monsoonal, with $95 \%$ of mean annual rainfall falling between April and November. According to the weather station at Batchelor (within $60 \mathrm{~km}$ of all fire measurement sites), mean annual rainfall is $1528 \mathrm{~mm}$, with a mean maximum temperature of $32^{\circ} \mathrm{C}$ in July and $37^{\circ} \mathrm{C}$ in October.

The opportunistic nature of this campaign allowed for emissions to be measured from fires in a number of different savanna land systems within the vicinity of Darwin. These included the gently undulating plains of the Koolpinyah land system (Christian et al., 1953), dominated by open eucalyptus woodland with tussock grasses (Fig. 5e and f). This vegetation class is similar to the tussock grass open woodland of the Arnhem Land campaigns and will also be indicated using TGOW. Measurements were also made at fires on the flat perennially flooded plains of the Marrakai land system (Christian et al., 1953), mainly consisting of tussock grasslands (Fig. 5g). This vegetation class will be referred to as "tussock grass floodplain" (TGFP). Fires were also measured on the flat country of the Batchelor land system (Christian et al., 1953), dominated by tall closed woodland with tussock and gamba (Andropogon gayanus) grasses (Fig. 5h). This vegetation class will be referred to as "tussock and gamba grass woodland" (TGGW).

Unlike the purely experimental fires of the Arnhem Land campaign, most of the fires measured for the Darwin region campaign were either wildfires or burn-off, where there was no control over the timing and pattern of ignition, and with many fires burning across many hectares. Locations of burn-off and wildfires were identified by regular monitoring of the NAFI website (http://www.firenorth.org.au), which shows the locations of satellite-detected fires; and by regular 
phone calls to Bushfires NT (Northern Territory Government), who are responsible for supporting landholders with fire mitigation.

Wildfires were measured at the Adelaide River station on Marrakai Road (TGFP) on 1 October 2010; near Lambells Lagoon off Arnhem Highway (TGOW) on 1 October 2010; and at Berry Springs (TGOW) on 4 October 2010. Burn-offs were measured at the Gould airstrip near Batchelor (TGGW) on 11 September 2010 and at Southport (TGOW) on 6 October 2010. In addition to the wildfires and burn-offs, measurements were made at a set of three experimental fires in the Territory Wildlife Park (TGOW) near Berry Springs on 5 October 2010. Each of the experimental plots was approximately $130 \times 80 \mathrm{~m}$ in size, and the fires and fire conditions from this campaign are presented in Table 1.

\section{Results}

A time series of smoke-tracer mole fractions retrieved from FTIR spectra collected near to the downwind boundary of one of the experimental fires is shown in Fig. 6, with $\mathrm{CO}_{2}$, $\mathrm{CO}$ and MCE shown in detail in Fig. 7. In most of the experimental burns (with the exception of the hummock grass plots), the fires were ignited with a back-burning fire line on the down-wind boundary of the fire plot; this fire moves slowly against the wind, forming a fire break. The up-wind boundary is then ignited, with the majority of the plot burning with a head fire driven by the prevailing wind. Generally, the smoke passing through the infrared beam will have first originated from the flaming combustion in the backburn fire line (notice the high MCE in the first minute of the time series in Fig. 7). Immediately following the initial burst of smoke from the flaming combustion, the smoke from the flaming back-burn will be mixing with smouldering smoke, also originating from the back-burn, with increasing $\mathrm{CO}$ mole fraction and a corresponding decrease in MCE (until $\sim 7$ mins in Fig. 7). As the back-burn fire line burns away from the OP-FTIR path, most of the smoke crossing the infrared beam will have been emitted from the steadily increasing area of smouldering-phase combustion, with contributions from both the flaming combustion of the head fire and the smouldering area behind the head fire (towards the end of the time series in Fig. 7, as MCE decreases to 90\% and below). This equates to the area of "flaming combustion" (i.e. the fire line) and the associated "smoking zone" of smouldering combustion located close behind the fire front, as detailed in the OP-FTIR African savannah measurements of Wooster et al. (2011).

\subsection{Emission ratios}

The emission ratios of each trace gas relative to $\mathrm{CO}_{2}$ and $\mathrm{CO}$ are calculated using the generalised least squares linear regression slope (this is the best fit to the points that minimises

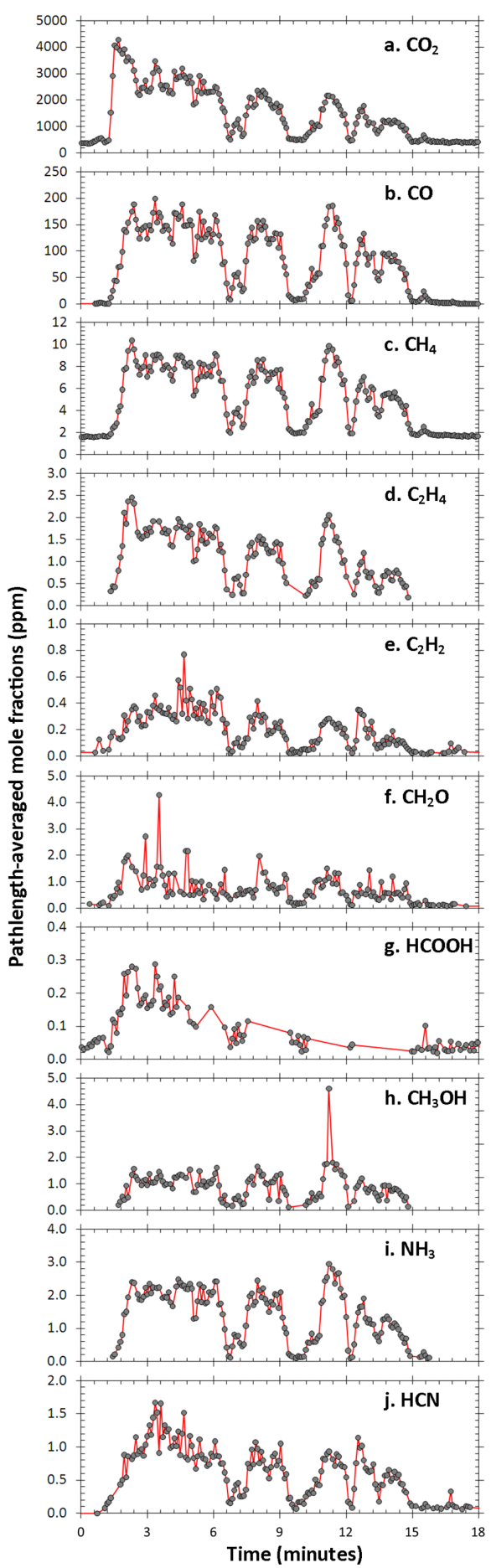

Figure 6. Time series of path-averaged trace gas mole fractions (in ppm) for plot LD-TGOW-A (30 September 2009) during the latedry season Arnhem Land campaign. Trace gas path-averaged mole fractions were retrieved from the OP-FTIR spectra using MALT. An example smoke spectrum with the best-fit modelled spectrum for each of the spectral windows used to retrieve the mole fraction of each of the trace gases presented in this figure can be found in Fig. 2. Gaps in the time series of specific trace gases are due to periods of low signal-to-noise within the spectral window used for the retrieval of that particular gas. 
deviations from the line of fit in both the $x$ and $y$ axes, weighted by uncertainties in both $x$ and $y$ ) of the trace gas species mole fraction versus the $\mathrm{CO}_{2}$ or $\mathrm{CO}$ mole fraction. As an example, Figs. 8 and 9 show a series of trace gas mole fractions plotted against $\mathrm{CO}_{2}$ and $\mathrm{CO}$, respectively. The generalised least squares linear best fits are shown in each case,

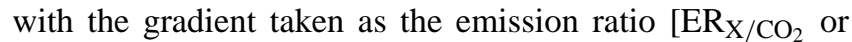
$\mathrm{ER}_{\mathrm{X} / \mathrm{CO}}$. As is evident in both Figs. 8 and 9, it is clear that for all gases there is a stronger correlation to $\mathrm{CO}$ than to $\mathrm{CO}_{2}$ (due to their preferential production during smoulderingphase combustion, as is also the case for $\mathrm{CO}$ ). For most gases $\left(\mathrm{CH}_{4}, \mathrm{C}_{2} \mathrm{H}_{2}, \mathrm{C}_{2} \mathrm{H}_{4}, \mathrm{C}_{2} \mathrm{H}_{6}, \mathrm{CH}_{3} \mathrm{OH}, \mathrm{CH}_{3} \mathrm{COOH}, \mathrm{HCOOH}\right.$, $\mathrm{NH}_{3}, \mathrm{HCN}$ ), their emission ratio to $\mathrm{CO}$ is used for the calculation of their respective emission factors. For $\mathrm{H}_{2} \mathrm{CO}$, the only gas to show a better mean correlation with $\mathrm{CO}_{2}$ (across all 21 fires), the emission ratio to $\mathrm{CO}_{2}$ is used for the calculation of its emission factor (Paton-Walsh et al. (2014) also found $\mathrm{C}_{2} \mathrm{H}_{4}$ to be better correlated to $\mathrm{CO}_{2}$ ). Following Sinha et al. (2003) and Wooster et al. (2011), the strength of the coefficient of determination $\left(R^{2}\right)$ between the mole fractions of each target gas and that of $\mathrm{CO}$ or $\mathrm{CO}_{2}$ is used to confirm whether the emission ratio for the target gas is well determined. For gases with stronger IR absorption features (e.g. $\mathrm{CO}, \mathrm{CH}_{4}, \mathrm{C}_{2} \mathrm{H}_{4}, \mathrm{NH}_{3}$ ), $R^{2}$ in the figures was generally higher than 0.8 , whilst gases with weaker IR absorption (e.g. $\mathrm{CH}_{3} \mathrm{OH}, \mathrm{HCN}, \mathrm{HCOOH}$ ) showed poorer correlations to $\mathrm{CO}_{2}$ and $\mathrm{CO}$, due to greater uncertainties in the retrieval process. Those species for which the coefficient of determination fell below 0.4 are assumed to have poorly determined emission ratios (Sinha et al., 2003; Wooster et al., 2011). Consequently, emission ratios where $R^{2}$ fell below 0.4 were not used in the calculation of emission factors.

Given that MCE is known to decrease as the fire progresses through the plot (Fig. 7), with a greater contribution from the increasing area of smouldering combustion behind the fire front, it is assumed that measurements with the highest MCE are of smoke that has predominantly originated from flaming combustion, whilst those measurements with lower MCE are of smoke that has a higher proportion of smouldering combustion (Yokelson et al., 1996). Whilst the within-fire variation in emission ratios is quite limited, as shown by the high value of $R^{2}$ on the linear least squares regression fits in the bivariate plots (Figs. 8 and 9), this ever-changing ratio of flaming-to-smouldering smoke does lead to some variation in the emission ratio of most of the gases to $\mathrm{CO}_{2}$ (as evident in the deviation from the linear best-fit in most of the scatter plots shown in Fig. 8). To account for this, it is possible to calculate different emission ratios to $\mathrm{CO}_{2}$ for the different combustion stages of each fire. Conventionally, laboratory studies use observations of fire activity to determine the combustion stage of emissions (e.g. Yokelson et al., 1996) or an approach where the maximum rate of increase of $\mathrm{CO}$ emission is taken as the beginning of the smouldering stage (e.g. Lobert et al., 1991). The OP-FTIR study of Wooster et al. (2011) had access to simultaneous airborne imaging, so

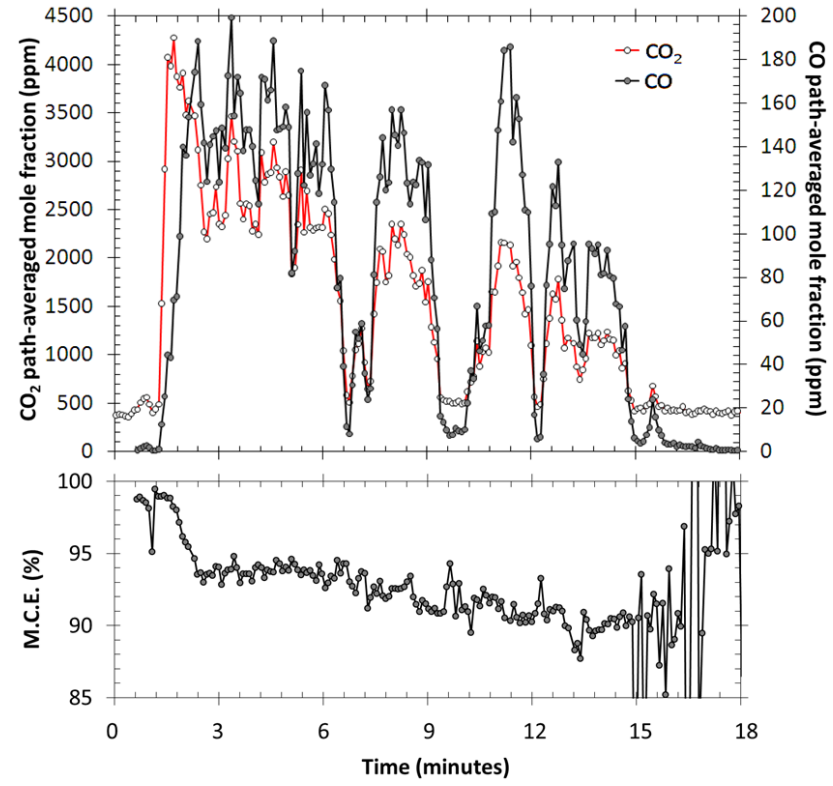

Figure 7. (top) Time series of retrieved $\mathrm{CO}_{2}$ and $\mathrm{CO}$ path-lengthaveraged mole fractions, and (bottom) modified combustion efficiency (MCE). These data are taken from LD-TGOW-A (30 September 2009). The full suite of gas mole fractions are presented in Fig. 6.

was able to separate out times of different fire activity based on those thermal/optical airborne observations. Here, measured emissions cannot be ascribed to particular combustion stages using observations, and furthermore the relative contribution to measured emissions from flaming and smouldering combustion may vary depending on changes in the wind direction, ignition pattern of the fire, and heterogeneous vegetation cover and fuel moisture within the fire plot. Instead, the emissions measurements are split by MCE, so that measurements with high MCE (>90\%) and those with low MCE $(<90 \%)$ may be used separately to calculate emission ratios (Fig. 10). This approach has been used in the past for laboratory analysis, and the $90 \%$ threshold was taken from studies that have published MCE for flaming and smouldering combustion stages (e.g. Lobert et al., 1991; Yokelson et al., 1996; Bertschi et al., 2003b). Emission ratios of each target species to both $\mathrm{CO}_{2}$ and $\mathrm{CO}$ were assessed in this way and are presented in Tables 2 and 3, respectively, in addition to emission ratios derived from all measurements.

As discussed above, the within-fire variation in emission ratios is fairly limited, and can be understood by splitting measurements by MCE as already described. The betweenfire variation, however, is larger, with the flaming emission ratio of $\mathrm{CH}_{4}$, for example, varying from 0.0010 (for spinifex) to 0.0045 for one of the tussock grass open woodland plots. Most of this variation is caused by comparison between the "landscape" experimental fires (those that incorporate a number of fuel species; e.g. TGOW, HGOW, SOW) and 

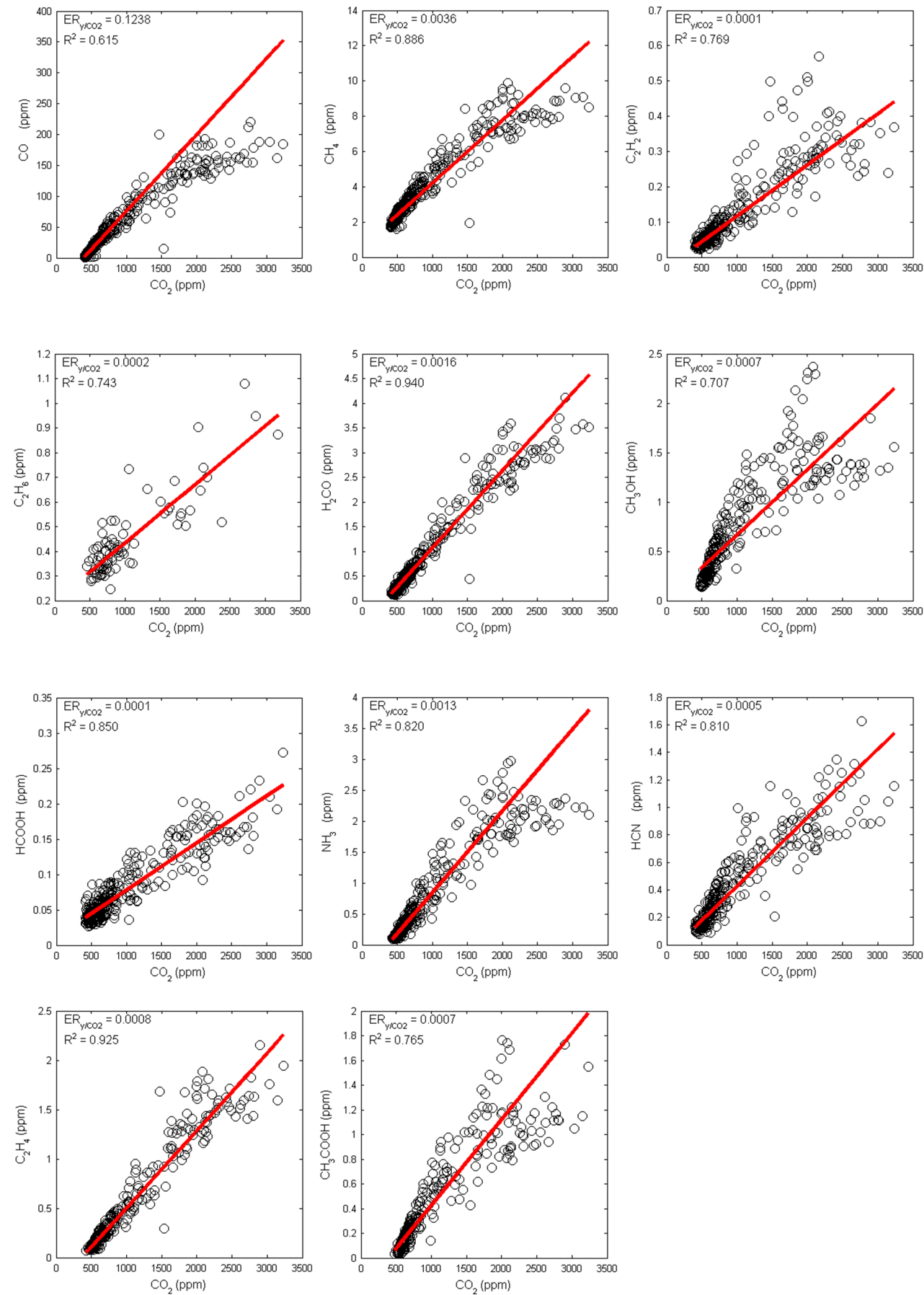

Figure 8. Example scatter plots of the measured trace gas path-length-averaged mole fractions used to calculate emission ratios. The data presented here are from LD-TGOW-A (30 September 2009). The slope of the least squares linear best fit to these data (thick red line) is used to derive the relevant emission ratio $\left(\mathrm{ER}_{\mathrm{x} / \mathrm{CO}_{2}}\right)$. For each of the 10 trace gases shown above, the emission ratio and the $R^{2}$ is given towards the top of each plot. The equivalent plots for emission ratios to $\mathrm{CO}$ are presented in Fig. 9.

the experimental fires that were conducted on the individual clumps of spinifex. Given that the spinifex measured here appeared to burn with high combustion efficiency (possibly due to measured high burn temperature, aerated structure, and leaf resin content), producing little observable "smoke" (see
Fig. 5d), it is perhaps no surprise that its emissions characteristics are different from those from experimental fires containing multiple species, where vegetation that burn at different combustion efficiencies contribute to a plume-averaged efficiency (e.g. the tussock grass and hummock grass open 

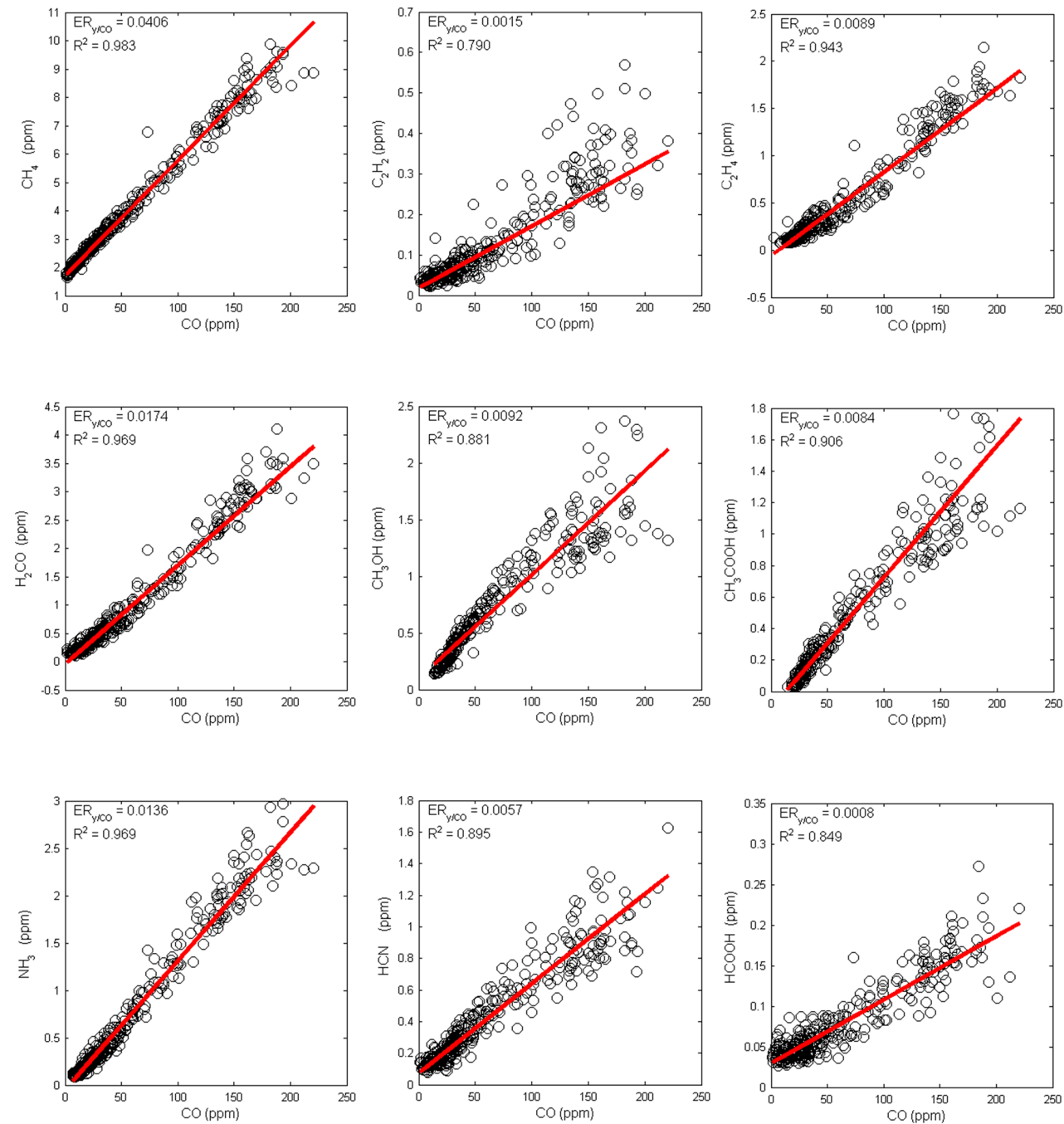

Figure 9. Same as Fig. 8, but with relation to $\mathrm{CO}$.

woodland landscapes consist of both fine and coarse fuels, each with different structure and degrees of compaction). As the purpose of this work is to characterise landscapeaveraged emissions, the emission ratios and emission factors from the spinifex fires have been excluded from calculating average emissions parameters.

The emission ratios presented in Table $2\left(\mathrm{ER}_{\left.\mathrm{X} / \mathrm{CO}_{2}\right)}\right.$ and Table $3\left(\mathrm{ER}_{\mathrm{X} / \mathrm{CO}}\right)$ show the mean emission ratios for the landscape fire measurements (including HGOW, SOW, TGFP, TGGW, TGOW vegetation classes), excluding those derived from individual species fires (SPIN). Table 2 confirms that the emission ratios to $\mathrm{CO}_{2}$ (i.e. $\mathrm{ER}_{\mathrm{x} / \mathrm{CO}_{2}}$ ), for all of the gases investigated here, are higher in the measurements we class as "smouldering" (based on MCE < $90 \%$ ) than in those measurements classed as "flaming" (MCE $>90 \%$ ). The close correlation between the emissions of gases and those of $\mathrm{CO}$ (Fig. 9) also explains why there is no significant difference in the emission ratios to $\mathrm{CO}$
$\left(\mathrm{ER}_{\mathrm{x} / \mathrm{CO}}\right)$ recorded during these "flaming" and "smouldering" classes (the difference between "flaming" and "smouldering" $\mathrm{ER}_{\mathrm{x} / \mathrm{CO}}$ is smaller than the standard deviation of each ER). For formaldehyde $\left(\mathrm{H}_{2} \mathrm{CO}\right)$, the higher emission ratio to $\mathrm{CO}$ during the "flaming" class might be due to the production of formaldehyde during the closely related (in space and time) pyrolysis combustion phase (Lobert and Warnatz, 1993); with some of the pyrolysed gas escaping combustion due to advective or convective winds. Wooster et al. (2011) suggested pyrolysis was the cause of the similarly higher OPFTIR derived emission ratios to $\mathrm{CO}$ for formaldehyde in the flaming rather than the residual smoldering combustion stage of southern African savannah fires.

\subsection{Drivers of variations in emission ratios and emission factors}

Figures 8 and 9 depict trace gas retrievals and emission ratios derived from data of a typical experimental fire. Given 
Table 2. Mean emission ratios for compound $X$ with respect to $\mathrm{CO}_{2}\left(\mathrm{ER}_{\mathrm{X} / \mathrm{CO}_{2}}\right)$ calculated from OP-FTIR measurements at 21 tropical savanna fires over the three campaigns to the Northern Territory. The standard deviation of the emission ratios is also included.

\begin{tabular}{lccc}
\hline Gas & $\begin{array}{c}\text { All measurements } \\
\mathrm{ER}_{\mathrm{X} / \mathrm{CO}_{2}} \pm \mathrm{SD}\end{array}$ & $\begin{array}{c}\text { Flaming* } \\
\mathrm{ERX} / \mathrm{CO}_{2} \pm \mathrm{SD}\end{array}$ & $\begin{array}{c}\text { Smouldering* } \\
\mathrm{ER} / \mathrm{CO}_{2} \pm \mathrm{SD}\end{array}$ \\
\hline $\mathrm{CO}$ & $0.0949 \pm 0.0351$ & $0.0814 \pm 0.0262$ & $0.1353 \pm 0.0396$ \\
$\mathrm{CH}_{4}$ & $0.00281 \pm 0.00183$ & $0.00213 \pm 0.00100$ & $0.00483 \pm 0.00142$ \\
$\mathrm{C}_{2} \mathrm{H}_{2}$ & $0.00010 \pm 0.00004$ & $0.00009 \pm 0.00004$ & $0.00016 \pm 0.00013$ \\
$\mathrm{C}_{2} \mathrm{H}_{4}$ & $0.00046 \pm 0.00021$ & $0.00039 \pm 0.00022$ & $0.00061 \pm 0.00032$ \\
$\mathrm{C}_{2} \mathrm{H}_{6}$ & $0.00017 \pm 0.00014$ & $0.00010 \pm 0.00002$ & $0.00018 \pm 0.00009$ \\
$\mathrm{H}_{2} \mathrm{CO}$ & $0.00139 \pm 0.00044$ & $0.00119 \pm 0.00026$ & $0.00186 \pm 0.00078$ \\
$\mathrm{CH}_{3} \mathrm{OH}$ & $0.00062 \pm 0.00057$ & $0.00039 \pm 0.00021$ & $0.00087 \pm 0.00059$ \\
$\mathrm{CH}_{3} \mathrm{COOH}$ & $0.00055 \pm 0.00023$ & $0.00046 \pm 0.00021$ & $0.00103 \pm 0.00037$ \\
$\mathrm{HCOOH}$ & $0.00010 \pm 0.00006$ & $0.00010 \pm 0.00007$ & $0.00010 \pm 0.00003$ \\
$\mathrm{HCN}$ & $0.00048 \pm 0.00025$ & $0.00037 \pm 0.00019$ & $0.00067 \pm 0.00024$ \\
$\mathrm{NH}_{3}$ & $0.00091 \pm 0.00058$ & $0.00077 \pm 0.00042$ & $0.00170 \pm 0.00069$ \\
\hline * The "flaming" and "smouldering" classes are defined on the basis of an MCE threshold of $90 \%$, as \\
detailed in the main text.
\end{tabular}

that a number of different vegetation types were sampled during the three Australian campaigns, with measurements made throughout the early and late dry season, and the likelihood that each experimental fire would have burned at different efficiencies depending on the fuel and meteorological conditions, it is important to assess the relative importance of each of these variables. Figure 11 includes all data from the 2009 campaigns, showing the scatter plot for $\mathrm{CH}_{4}$ vs. $\mathrm{CO}_{2}$ only, with each subplot $(\mathrm{a}-\mathrm{c})$ depicting the same data but with each data point (i.e. each individual retrieval from four co-added spectra collected over $\sim 5 \mathrm{~s}$ ) colour-coded depending on its MCE (Fig. 11a); the season of the experimental fire (Fig. 11b); and the predominant vegetation type for the burn (Fig. 11c). As discussed above, the between-fire variation in emission ratios can be primarily explained by a dependence on vegetation class (as is evident in Fig. 11c), with the spinifex (individual species) fires grouping towards the lower emission ratios and the sorghum dominated fires grouping towards the higher emission ratios. Figure 11a clearly demonstrates that this grouping is mainly a result of differences in the combustion efficiencies of these different vegetation classes, with MCE appearing to be the major control on the emission ratio slope, despite differences in vegetation classes. There is no clear pattern to discern when the data are plotted by season (Fig. 11b).

By sub-sampling the data in Fig. 11a into $2 \%$ bins of MCE (e.g. only measurements where $80 \%<\mathrm{MCE} \leq 82 \%$ ), it is possible to calculate a range of emission ratios to $\mathrm{CO}_{2}$ depending on MCE. Figure 12 depicts 11 different $\mathrm{CH}_{4}$

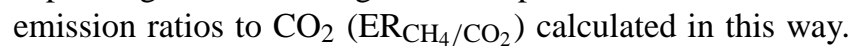
This figure demonstrates the strong relationship between the emission ratio of methane and the modified combustion efficiency, which is unsurprising due to the well-defined $\mathrm{CO}$ to $\mathrm{CO}_{2}$ and $\mathrm{CH}_{4}$ to $\mathrm{CO}$ emission ratios already shown in Fig. 9. A clear relationship between the slope of the linear
Table 3. Same as Table 2, but for mean emission ratios for compound $X$ with respect to $\mathrm{CO}\left(\mathrm{ER}_{\mathrm{X} / \mathrm{CO}}\right)$.

\begin{tabular}{lccc}
\hline Gas & $\begin{array}{c}\text { All measurements } \\
\mathrm{ER}_{\mathrm{X} / \mathrm{CO} \pm \mathrm{SD}}\end{array}$ & $\begin{array}{c}\text { Flaming } \\
\mathrm{ER}_{\mathrm{X} / \mathrm{CO}} \pm \mathrm{SD}\end{array}$ & $\begin{array}{c}\text { Smouldering } \\
\mathrm{ER}_{\mathrm{X} / \mathrm{CO}} \pm \mathrm{SD}\end{array}$ \\
\hline $\mathrm{CO}_{2}$ & $12.07 \pm 4.62$ & $13.39 \pm 3.96$ & $7.79 \pm 1.57$ \\
$\mathrm{CH}_{4}$ & $0.0399 \pm 0.0072$ & $0.0384 \pm 0.0051$ & $0.0402 \pm .0092$ \\
$\mathrm{C}_{2} \mathrm{H}_{2}$ & $0.0011 \pm 0.0006$ & $0.0014 \pm 0.0007$ & $0.0012 \pm 0.0009$ \\
$\mathrm{C}_{2} \mathrm{H}_{4}$ & $0.0057 \pm 0.0018$ & $0.0058 \pm 0.0026$ & $0.0048 \pm 0.0025$ \\
$\mathrm{C}_{2} \mathrm{H}_{6}$ & $0.0014 \pm 0.0010$ & $0.0010 \pm 0.0001$ & $0.0014 \pm 0.0006$ \\
$\mathrm{H}_{2} \mathrm{CO}$ & $0.0182 \pm 0.0028$ & $0.0202 \pm 0.0044$ & $0.0148 \pm 0.0055$ \\
$\mathrm{CH}_{3} \mathrm{OH}$ & $0.0083 \pm 0.0038$ & $0.0074 \pm 0.0021$ & $0.0080 \pm 0.0050$ \\
$\mathrm{CH}_{3} \mathrm{COOH}$ & $0.0081 \pm 0.0014$ & $0.0082 \pm 0.0016$ & $0.0079 \pm 0.0035$ \\
$\mathrm{HCOOH}$ & $0.0008 \pm 0.0002$ & $0.0010 \pm 0.0003$ & $0.0008 \pm 0.0002$ \\
$\mathrm{HCN}$ & $0.0053 \pm 0.0024$ & $0.0048 \pm 0.0023$ & $0.0051 \pm 0.0021$ \\
$\mathrm{NH}_{3}$ & $0.0129 \pm 0.0042$ & $0.0128 \pm 0.0041$ & $0.0128 \pm 0.0055$ \\
\hline
\end{tabular}

least squares regression lines and MCE is evident as the slope increases systematically with decreasing MCE. This relationship applies for the other trace gases that also correlate well with carbon monoxide. These MCE-dependent emission ratios can then be used to calculate MCE-dependent emission factors, discussed further below.

\subsection{Final emission factors}

Emission factors for $\mathrm{CO}_{2}$ and $\mathrm{CO}$ for each fire were calculated by the summation method as described in Paton-Walsh et al. (2014). Emission factors for all other gases were calculated from the $\mathrm{CO}_{2}$ and $\mathrm{CO}$ emission factors for the relevant fires and the emission ratio to $\mathrm{CO}_{2}$ or $\mathrm{CO}$ (given in Tables 2 and 3). These emission factors are presented in Table 4. Mean emission factors calculated from the individual fire emission factors in Table 4 are listed in Table 5.

By combining measurements from all fires, it is possible to build a detailed understanding of the relationship between MCE and emission ratios (as depicted earlier in Figs. 11a 
Table 4. Emission factors ( $\mathrm{g} \mathrm{kg}^{-1}$ of dry fuel burned) for each individual fire, calculated using the standardised method outlined in PatonWalsh et al. (2014). Uncertainties were calculated in quadrature from those associated with the trace gas emission ratios and a $\pm 10 \%$ uncertainty in the assumed fuel carbon.

\begin{tabular}{|c|c|c|c|c|c|c|c|c|c|c|c|c|}
\hline & $\mathrm{CO}_{2}$ & $\mathrm{CO}$ & $\mathrm{CH}_{4}$ & $\mathrm{C}_{2} \mathrm{H}_{2}$ & $\mathrm{C}_{2} \mathrm{H}_{4}$ & $\mathrm{C}_{2} \mathrm{H}_{6}$ & $\mathrm{CH}_{2} \mathrm{O}$ & $\mathrm{CH}_{3} \mathrm{OH}$ & $\mathrm{CH}_{3} \mathrm{COOH}$ & $\mathrm{HCOOH}$ & $\mathrm{HCN}$ & $\mathrm{NH}_{3}$ \\
\hline & EF unc & EF unc & $\mathrm{EF}$ unc & $\mathrm{EF}$ unc & $\mathrm{EF}$ unc & $\mathrm{EF}$ unc & $\mathrm{EF}$ unc & $\mathrm{EF}$ unc & EF unc & EF unc & EF unc & EF unc \\
\hline LD-TGOW-A & $1638 \pm 164$ & $110 \pm 18$ & $2.56 \pm 0.41$ & $0.16 \pm 0.03$ & $0.82 \pm 0.08$ & $\mathrm{nr} \pm \mathrm{nr}$ & $1.76 \pm 0.18$ & $1.15 \pm 0.18$ & $1.97 \pm 0.32$ & $0.14 \pm 0.02$ & $0.60 \pm 0.10$ & $0.91 \pm 0.15$ \\
\hline LD-TGOW-B & $03 \pm 160$ & $34 \pm 21$ & $22 \pm 0.51$ & $.11 \pm 0.02$ & $.64 \pm 0.06$ & & $2.08 \pm 0.21$ & $1.20 \pm 0.19$ & & $0.12 \pm 0.02$ & & \\
\hline LD-SOW-A & $28 \pm 153$ & $9 \pm 27$ & $94 \pm 0.95$ & $18 \pm 0.03$ & $0.75 \pm 0.08$ & & $2.43 \pm 0.24$ & $3.76 \pm 0.60$ & $3.28 \pm 0.52$ & $0.31 \pm 0.05$ & $1.12 \pm 0.18$ & $1.63 \pm 0.26$ \\
\hline LD-SPIN & $716 \pm 172$ & $75 \pm 12$ & $.28 \pm 0.20$ & $0.18 \pm 0.03$ & $0.11 \pm 0.01$ & $\mathrm{nr} \pm \mathrm{nr}$ & $0.53 \pm 0.05$ & $\mathrm{nr} \pm \mathrm{nr}$ & & & $0.36 \pm 0.06$ & $0.61 \pm 0.10$ \\
\hline LD-HGOW & $562 \pm 166$ & $100 \pm 16$ & $2.01 \pm 0.32$ & $0.09 \pm 0.01$ & $0.24 \pm 0.02$ & $\mathrm{nr} \pm \mathrm{nr}$ & $\mathrm{nr} \pm \mathrm{nr}$ & $0.67 \pm 0.11$ & $1.57 \pm 0.25$ & & $0.66 \pm 0.11$ & $0.51 \pm 0.08$ \\
\hline ED-TGO & $669 \pm 167$ & $96 \pm 15$ & $1.92 \pm 0.31$ & $\mathrm{nr} \pm \mathrm{nr}$ & $0.16 \pm 0.02$ & $0.04 \pm 0.01$ & $1.44 \pm 0.14$ & $\mathrm{nr} \pm \mathrm{nr}$ & $0.96 \pm 0.15$ & & & \\
\hline GOW-B & $579 \pm 168$ & $87 \pm 14$ & $1.81 \pm 0.29$ & $\mathrm{nr} \pm \mathrm{nr}$ & $0.74 \pm 0.07$ & $\mathrm{nr} \pm \mathrm{nr}$ & $\mathrm{nr} \pm \mathrm{nr}$ & $0.81 \pm$ & & & & \\
\hline ED-SOW-A & $570 \pm 167$ & $92 \pm 15$ & $2.16 \pm 0.35$ & $\mathrm{nr} \pm \mathrm{nr}$ & $0.52 \pm 0.05$ & $\mathrm{nr} \pm \mathrm{nr}$ & $1.54 \pm 0.15$ & $0.99 \pm$ & .31 & $=0.03$ & $\mathrm{nr}$ & 0.58 \\
\hline W-B & $624 \pm 162$ & $118 \pm 19$ & $2.87 \pm 0.46$ & $0.07 \pm 0.01$ & $0.56 \pm 0.06$ & $\mathrm{nr} \pm \mathrm{nr}$ & $1.39 \pm 0.14$ & $1.48 \pm 0.24$ & $2.64 \pm 0.42$ & $\mathrm{nr}=$ & $0.17 \pm 0.03$ & $0.97 \pm 0.16$ \\
\hline ED- & $763 \pm 176$ & $39 \pm 6$ & $0.71 \pm 0.11$ & $\mathrm{nr} \pm \mathrm{nr}$ & $\mathrm{nr} \pm \mathrm{nr}$ & $\mathrm{nr} \pm \mathrm{nr}$ & $\mathrm{nr} \pm \mathrm{nr}$ & $\mathrm{nr}+\mathrm{pr}$ & $\mathrm{nr} \pm \mathrm{nr}$ & & & $\mathrm{nr} \pm \mathrm{nr}$ \\
\hline BAT- & $1713 \pm 171$ & $60 \pm 10$ & $1.65 \pm 0.26$ & $\mathrm{nr} \pm \mathrm{nr}$ & $\mathrm{nr} \pm \mathrm{nr}$ & $\mathrm{nr} \pm \mathrm{nr}$ & $\mathrm{nr} \pm \mathrm{nr}$ & $\mathrm{nr} \pm \mathrm{nr}$ & 0.16 & & & 0.07 \\
\hline ARS- & $1746 \pm 175$ & $45 \pm 7$ & $1.11 \pm 0.18$ & $\mathrm{nr} \pm \mathrm{nr}$ & $\mathrm{nr} \pm \mathrm{nr}$ & $\mathrm{nr} \pm \mathrm{nr}$ & $1.35 \pm 0.13$ & $\mathrm{nr} \pm \mathrm{nr}$ & & & $\mathrm{nr} \pm \mathrm{nr}$ & $=0.06$ \\
\hline ARS-TGFP-B & $1676 \pm 168$ & $86 \pm 14$ & $1.61 \pm 0.26$ & $0.13 \pm 0.02$ & $\mathrm{nr} \pm \mathrm{nr}$ & $0.07 \pm 0.01$ & $1.62 \pm 0.16$ & $0.69 \pm 0.11$ & & $\mathrm{nr} \pm \mathrm{nr}$ & $0.32 \pm 0.05$ & $=0.10$ \\
\hline & $1695 \pm 169$ & $76 \pm 12$ & $1.45 \pm 0.23$ & $\mathrm{nr} \pm \mathrm{nr}$ & $0.34 \pm 0.03$ & $\mathrm{nr} \pm \mathrm{nr}$ & $1.34 \pm 0.13$ & $0.62 \pm 0.10$ & & & & $0.51 \pm 0.08$ \\
\hline ARS-TGFP-D & $1746 \pm 175$ & $46 \pm 7$ & $0.84 \pm 0.13$ & $0.10 \pm 0.02$ & $0.29 \pm 0.03$ & $\mathrm{nr} \pm \mathrm{nr}$ & $1.36 \pm 0.14$ & $\mathrm{nr} \pm \mathrm{nr}$ & $0.87 \pm 0.14$ & $0.07 \pm 0.01$ & $0.38 \pm 0.06$ & $0.35 \pm 0.06$ \\
\hline & $1736 \pm 174$ & $49 \pm 8$ & $1.09 \pm 0.17$ & $\mathrm{nr} \pm \mathrm{nr}$ & $\mathrm{nr} \pm \mathrm{nr}$ & $\mathrm{nr} \pm \mathrm{nr}$ & $\mathrm{nr} \pm \mathrm{nr}$ & $0.39 \pm 0.06$ & $\mathrm{nr} \pm \mathrm{nr}$ & $\mathrm{nr} \pm \mathrm{nr}$ & $\mathrm{nr} \pm \mathrm{nr}$ & $\mathrm{nr} \pm \mathrm{nr}$ \\
\hline & $1695 \pm 170$ & $76 \pm 12$ & $1.79 \pm 0.29$ & $\mathrm{nr} \pm \mathrm{nr}$ & & $\mathrm{nr} \pm \mathrm{nr}$ & $1.09 \pm 0.11$ & $0.70 \pm 0.11$ & & & & $0.84 \pm 0.14$ \\
\hline GOW-A & $1740 \pm 174$ & $49 \pm 8$ & $1.15 \pm 0.18$ & $\mathrm{nr} \pm \mathrm{nr}$ & $\mathrm{nr} \pm$ & $\mathrm{nr} \pm$ & $1.04 \pm 0.10$ & $0.44 \pm 0.07$ & $0.94 \pm$ & $\mathrm{nr} \pm \mathrm{nr}$ & $\mathrm{nr}=$ & $0.54 \pm 0.09$ \\
\hline & $1655 \pm 165$ & $96 \pm 15$ & $2.60 \pm 0.42$ & & & & & & & $0.14 \pm 0.02$ & & $1.24 \pm 0.20$ \\
\hline & $1627 \pm 163$ & $114 \pm 18$ & $3.06 \pm 0.49$ & $0.07 \pm 0.01$ & $0.46 \pm 0.05$ & $0.13 \pm 0.02$ & $2.32 \pm 0.23$ & $0.87 \pm 0.14$ & $1.54 \pm 0.25$ & $0.14 \pm 0.02$ & & $1.04 \pm 0.17$ \\
\hline SPT-TGOW & $1721 \pm 172$ & $59 \pm 9$ & $1.23 \pm 0.20$ & $\mathrm{nr} \pm \mathrm{nr}$ & $0.31 \pm 0.03$ & $\mathrm{nr} \pm \mathrm{nr}$ & $0.99 \pm 0.10$ & $\mathrm{nr} \pm \mathrm{nr}$ & $1.21 \pm 0.19$ & $\mathrm{nr} \pm \mathrm{nr}$ & $\mathrm{nr} \pm \mathrm{nr}$ & $0.49 \pm 0.08$ \\
\hline
\end{tabular}

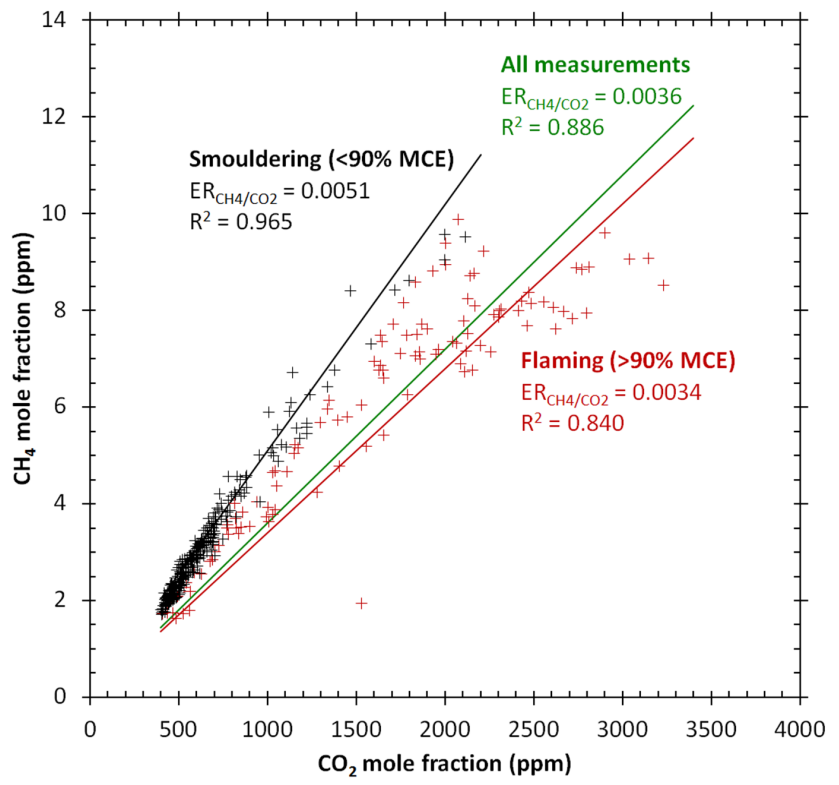

Figure 10. An example scatter plot of the measured path-lengthaveraged mole fractions of $\mathrm{CO}_{2}$ and $\mathrm{CH}_{4}$ (as in Fig. 8, top centre). Here, the data have been split using MCE, with measurements having an MCE greater than $90 \%$ (red) being considered separately to those with a lower MCE (black). Different emission ratios and emission factors for flaming and smouldering emissions can then be determined (also shown on the plot in red and black text respectively, the green text indicates the emission ratio and factors determined using all data).

and 12). MCE-dependent emission ratios can be used to calculate MCE-dependent emission factors. Using the same methodology applied to calculate emission factors for individual fires, it is possible to calculate emission factors for each $2 \%$-MCE bin. Figure 13 shows the relationship between $\mathrm{MCE}$ and the emission factor of $\mathrm{CH}_{4}(\mathrm{EF} \mathrm{CH})$ calculated using the measurements from different vegetation classes and when using all measurements combined. This plot demonstrates that the majority of variation in the emission factor for $\mathrm{CH}_{4}$ is determined by MCE irrespective of vegetation type. The uncertainty bounds of the $\mathrm{CH}_{4}$ emission factor for any particular vegetation class lie within the bounds of the emission factor determined from all measurements for each MCE bin (except TGFP in the 86-88\% MCE bin).

\section{Comparison to past ER and EF measures}

The emission factors presented here are the first to be reported from OP-FTIR measurements of tropical savannas in Australia and follow only a few ground-based (Hurst et al., 1994a) and airborne studies (Hurst et al., 1994b; Shirai et al., 2003) in this ecosystem. The emission factors for $\mathrm{CH}_{3} \mathrm{OH}$, $\mathrm{CH}_{3} \mathrm{COOH}$, and $\mathrm{HCOOH}$ are the first to be reported by any methodology for Australian savanna fires (Table 5). The emission factors presented here have been estimated from measurements at up to 21 separate fires from a variety of vegetation types and from both controlled experimental burns and wildfires (Table 4). Table 5 compares the emission factors reported here with those reported by previous studies of tropical savannas in Australia (listed above) and with those reported by the emission factor databases for global savanna and grasslands in Andreae and Merlet (2001) and global savannas in Akagi et al. (2011). 
Table 5. Emission factors ( $\mathrm{g} \mathrm{kg}^{-1}$ dry fuel burned) reported by this study and those for the same trace gases reported by previous Australian savanna studies (Hurst et al., 1994a, b; Shirai et al., 2003) and by Andreae and Merlet (2001) and Akagi et al. (2011) who estimate global savanna emission factors by amalgamating suite of emissions studies. For this study and the Australian savanna studies, the mean and standard deviation of the emission factor is calculated from individual fires.

\begin{tabular}{|c|c|c|c|c|c|c|c|}
\hline & \multicolumn{2}{|c|}{ This study } & \multicolumn{3}{|c|}{ Australian tropical savanna } & \multicolumn{2}{|c|}{ All savanna } \\
\hline & \multirow[b]{2}{*}{$\mathrm{EF}$} & \multirow[b]{2}{*}{ SD } & $\mathrm{Hu} 1994 \mathrm{a}$ & Hu1994b & $\operatorname{Sh} 2003$ & $\mathrm{AM} 2001^{\mathrm{a}}$ & $\mathrm{Ak} 2011^{\mathrm{b}}$ \\
\hline & & & $\mathrm{EF} \quad \mathrm{SD}$ & $\mathrm{EF} \quad \mathrm{SD}$ & $\mathrm{EF} \quad \mathrm{SD}$ & EF $\quad S D$ & EF $\quad \mathrm{NV}$ \\
\hline $\mathrm{CO}_{2}$ & \multicolumn{2}{|c|}{$1674 \pm 56$} & $1595 \pm 121$ & $1646 \pm 106$ & $1613 \pm 111$ & $1646 \pm 99$ & $1686 \pm 38$ \\
\hline $\mathrm{CO}$ & \multicolumn{2}{|c|}{$87 \pm 33$} & $91.4 \pm 27$ & $58.9 \pm 20$ & $88 \pm 8$ & $61 \pm 16$ & $63 \pm 17$ \\
\hline $\mathrm{CH}_{4}$ & \multicolumn{2}{|c|}{$2.10 \pm 1.16$} & $2.3 \pm 1.29$ & $2.3 \pm 0.79$ & $2.2 \pm 0.4$ & $2.2 \pm 0.8$ & $1.94 \pm 0.85$ \\
\hline $\mathrm{C}_{2} \mathrm{H}_{2}$ & \multicolumn{2}{|c|}{$0.11 \pm 0.04$} & $0.12 \pm 0.08$ & $0.10 \pm 0.05$ & $0.12 \pm 0.02$ & $0.27 \pm 0.22$ & $0.24 \pm 0.1$ \\
\hline $\mathrm{C}_{2} \mathrm{H}_{4}$ & \multicolumn{2}{|c|}{$0.49 \pm 0.22$} & $\mathrm{nr} \pm \mathrm{nr}$ & $0.53 \pm 0.24$ & $0.31 \pm 0.04$ & $0.84 \pm 0.46$ & $0.82 \pm 0.35$ \\
\hline $\mathrm{C}_{2} \mathrm{H}_{6}$ & \multicolumn{2}{|c|}{$0.08 \pm 0.05$} & $0.05 \pm 0.03$ & $0.07 \pm 0.02$ & $0.53 \pm 0.07$ & $0.32 \pm 0.15$ & $0.66 \pm 0.41$ \\
\hline $\mathrm{CH}_{2} \mathrm{O}$ & 1.57 & \pm 0.44 & $0.26 \pm 0.16$ & $\mathrm{nr} \pm \mathrm{nr}$ & $\mathrm{nr} \pm \mathrm{nr}$ & $0.71 \pm 0.42$ & $0.73 \pm 0.62$ \\
\hline $\mathrm{CH}_{3} \mathrm{OH}$ & 1.06 & \pm 0.87 & $\mathrm{nr} \pm \mathrm{nr}$ & $\mathrm{nr} \pm \mathrm{nr}$ & $\mathrm{nr} \pm \mathrm{nr}$ & $1.47 \pm 1.20-1.74$ & $1.18 \pm 0.41$ \\
\hline $\mathrm{CH}_{3} \mathrm{COOH}$ & 1.54 & \pm 0.64 & $\mathrm{nr} \pm \mathrm{nr}$ & $\mathrm{nr} \pm \mathrm{nr}$ & $\mathrm{nr} \pm \mathrm{nr}$ & $2.61 \pm 2.40-2.81$ & $3.55 \pm 1.47$ \\
\hline $\mathrm{HCOOH}$ & 0.16 & \pm 0.07 & $\mathrm{nr} \pm \mathrm{nr}$ & $\mathrm{nr} \pm \mathrm{nr}$ & $\mathrm{nr} \pm \mathrm{nr}$ & $0.63 \pm 0.62-0.63$ & $0.21 \pm 0.10$ \\
\hline $\mathrm{HCN}$ & 0.53 & \pm 0.31 & $0.03 \pm 0.02$ & $0.03 \pm 0.02$ & $\mathrm{nr} \pm \mathrm{nr}$ & $0.23 \pm 0.55$ & $0.41 \pm 0.15$ \\
\hline $\mathrm{NH}_{3}$ & 0.70 & \pm 0.36 & $1.53 \pm 0.86$ & $0.61 \pm 0.39$ & $\mathrm{nr} \pm \mathrm{nr}$ & $0.74 \pm 0.25$ & $0.52 \pm 0.35$ \\
\hline
\end{tabular}

${ }^{a}$ The emission factor reported by Andreae and Merlet (2001) is the mean emission factor of all of the contributing studies, and the standard deviation is that of the studies (unless only two studies were used for a particular emission factor, in which case, the uncertainty is represented by a range).

$\mathrm{b}$ The emission factor reported by Akagi et al. (2011) is the mean of the contributing studies, whilst the uncertainty is an indication of the natural variability of the emission factor estimated from the reported variability in the contributing studies.

\subsection{Carbonaceous species}

A broad range of emission factors for carbon dioxide (EF $\mathrm{CO}_{2}$ ) are reported in the literature from savanna ecosystems (Table 5). The emission factors reported here are higher than those reported by previous studies of northern Australian savanna fires, but fall within the standard deviation of measurements in northern Australia made by Hurst et al. (1994b) and Shirai et al. (2003). The EF $\mathrm{CO}_{2}$ reported here agrees well with those reported in Andreae and Merlet (2001 and subsequent updates in 2009), and Akagi et al. (2011), which draw on numerous studies in savanna ecosystems worldwide (the mean $\mathrm{EF} \mathrm{CO}_{2}$ reported here is only $0.7 \%$ smaller than that reported by Akagi et al. (2011) for savanna ecosystems).

The carbon monoxide emission factor (EF CO) reported here agrees well with previous studies of biomass burning in Australian tropical savannas, which appear to be slightly higher than the global average for savannas (Akagi et al., 2011) report an EF CO of $63 \mathrm{~g} \mathrm{~kg}^{-1}$, whilst the mean EF CO for the Australian studies, including this one, is $81 \mathrm{~g} \mathrm{~kg}^{-1}$ ). This might indicate that the efficiency of burning in Australian tropical savannas might be lower than the global savanna average; indeed, the global ecosystem averages include emissions from grasslands, which are believed to burn with higher MCE due to the relatively higher abundance of finer fuels than is found in woodland savannas (van Leeuwen and van der Werf et al., 2011).

For the methane emission factor $\left(\mathrm{EF} \mathrm{CH}_{4}\right)$, the EF reported here agrees with all of the previous Australian studies and the global savanna $\mathrm{EF} \mathrm{CH}_{4}$. The mean emission factors of $\mathrm{C}_{2} \mathrm{H}_{2}$ and $\mathrm{C}_{2} \mathrm{H}_{4}$ are both lower than those reported by Andreae and Merlet (2001) and Akagi et al. (2011), and are closer to those measured in the northern Australian studies (the mean $\mathrm{EF} \mathrm{C}_{2} \mathrm{H}_{2}$ and $\mathrm{EF} \mathrm{C}_{2} \mathrm{H}_{4}$ for the northern Australian studies, including this one, at $0.11 \mathrm{~g} \mathrm{~kg}^{-1}$ and $0.44 \mathrm{~g} \mathrm{~kg}^{-1}$ respectively, are both about half of those reported for global savannas).

The emission factor for formaldehyde $\left(\mathrm{EF}_{2} \mathrm{CO}\right)$ is sixtimes higher than the only previous study to report $\mathrm{EF} \mathrm{H}_{2} \mathrm{CO}$ for Australian savanna fires (Hurst et al. 1994a), but is in closer agreement to the estimates for global savannas (Andreae and Merlet, 2001; Akagi et al., 2011). Paton-Walsh et al. (2010) (who report emission ratios to CO, but not emission factors, for northern Australian fires from solar occultation FTIR measurements) also find that their emission ratio for $\mathrm{H}_{2} \mathrm{CO}$ is far higher than that reported in Hurst et al. (1994a) and suggest that one reason for this discrepancy might be that the $\mathrm{H}_{2} \mathrm{CO}$ measured by Hurst et al. (1994a), whose study was based on cryogenically stored samples, may have been subject to losses during sampling or storage. Both the OP-FTIR methodology used here and the methodology of Paton-Walsh et al. (2010) use long open-path measurements and so do not suffer from such problems associated with losses to the walls of sampling or storage equipment. Wooster et al. (2011), who also use a long open-path FTIR methodology, also find their $\mathrm{H}_{2} \mathrm{CO}$ emission factor for fires measured in Kruger National Park (South Africa) to 

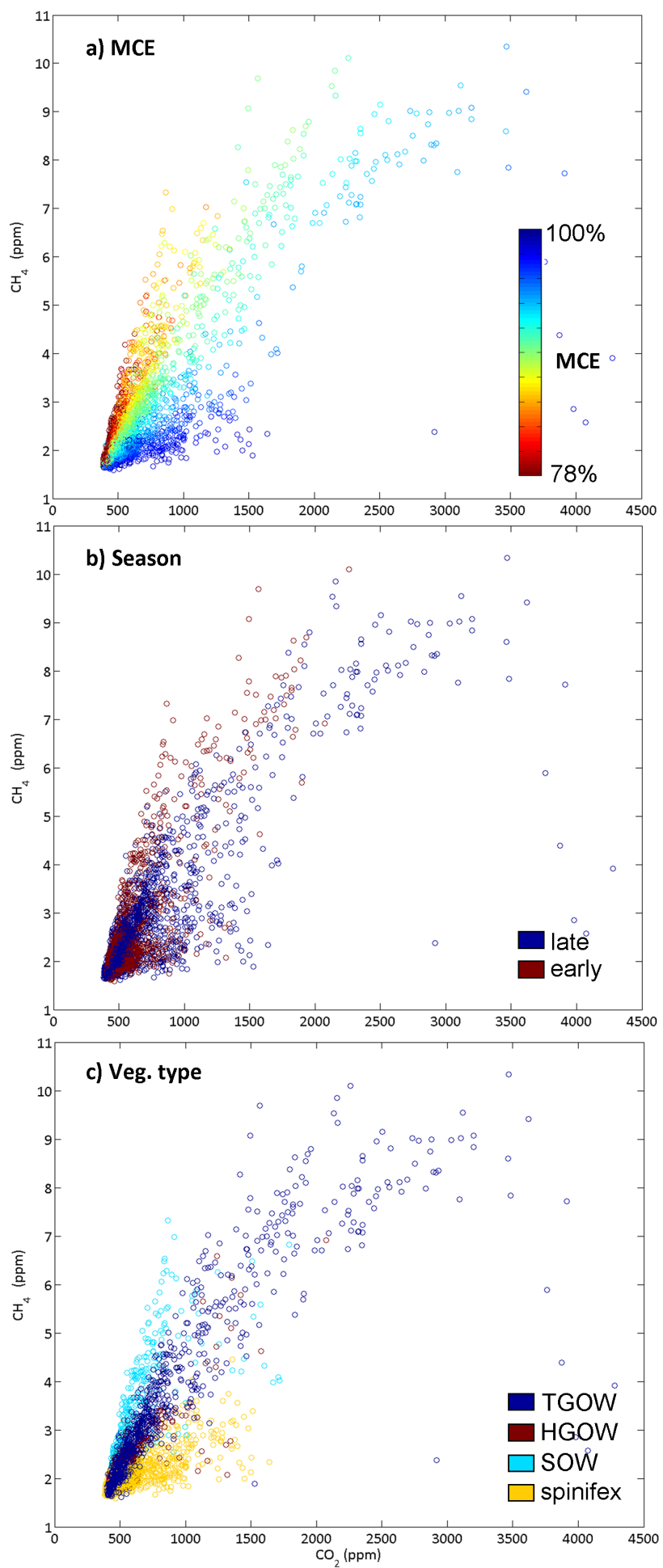

Figure 11. Scatter plots of the measured mole fractions of $\mathrm{CO}_{2}$ and $\mathrm{CH}_{4}$, including all measurements made during the two Arnhem Land campaigns in 2009. All three plots show the same data, but are colour-coded differently using (a) MCE; (b) season of measurement; and (c) vegetation class.

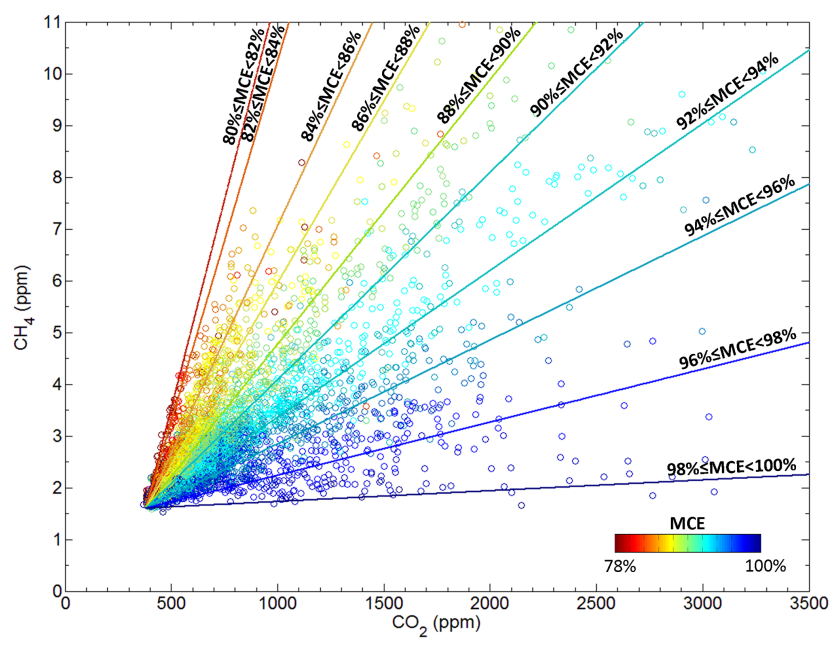

Figure 12. Same as Fig. 11a, but with all data from the 2009 and 2010 campaigns, including generalised least squares linear best-fit lines that have been calculated using measurements sub-sampled by narrow ( $2 \%$ ) bins of MCE. Each line represents the line of best fit to the sub-sampled emission measurements (the MCE bin for each line is indicated on the plot). Similar plots for other gas species can be found in Supplement Figs. S1 and S2.

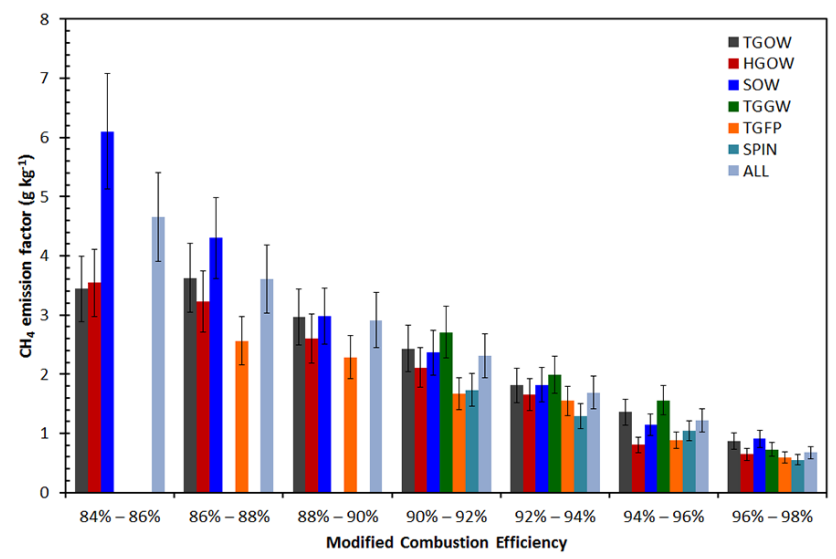

Figure 13. The emission factor for $\mathrm{CH}_{4}\left(\mathrm{EF} \mathrm{CH}_{4}\right)$ grouped by MCE, calculated using the emission ratios determined from $2 \%$ wide MCE bins for different vegetation classes, and for all measurements combined (error bars indicate the estimated uncertainty calculated in accordance with Paton-Walsh et al., 2014).

be significantly elevated compared with literature values for African savannah fires.

The emission factors for $\mathrm{CH}_{3} \mathrm{OH}, \mathrm{CH}_{3} \mathrm{COOH}$ and $\mathrm{HCOOH}$ are the first to be reported for Australian savannas. Globally, only two savanna studies report EFs for these gases in the database of Andreae and Merlet (2001, with 2009 updates), whilst the standard deviation for the EFs of these gases is high in Akagi et al. (2011) (ranging from 35-48\% of the mean $\mathrm{EF}$ ). $\mathrm{EF} \mathrm{HCOOH}$ and $\mathrm{EF} \mathrm{CH}_{3} \mathrm{OH}$ reported here lies closest to the latest estimates of Akagi et al. (2011) for 
global savannas, whilst $\mathrm{EF} \mathrm{CH}_{3} \mathrm{COOH}$ is somewhat lower than those reported in both Andreae and Merlet (2001) and Akagi et al. (2011). The number of studies that contribute to this "global" average, however, is limited (only two studies for $\mathrm{EF} \mathrm{CH}_{3} \mathrm{COOH}$ in Andreae and Merlet (2001, with 2009 updates) and five studies in Akagi et al., 2011), and it is likely that the lower emission factor reported here is within the realms of natural variability for $\mathrm{CH}_{3} \mathrm{COOH}$ emissions.

\subsection{Nitrogeneous species}

There is a very clear discrepancy between the emission factors for $\mathrm{HCN}(\mathrm{EF} \mathrm{HCN})$ reported here and those from Hurst et al. (1994a) and Hurst et al. (1994b). EF HCN reported here is over an order of magnitude higher than those from the previous Australian savanna studies. As was the case for $\mathrm{H}_{2} \mathrm{CO}$, Paton-Walsh et al. (2010) also find their measured emission ratio of $\mathrm{HCN}$ to $\mathrm{CO}$ to be over 6 times higher and 3 times higher than that of Hurst et al. (1994a) and Hurst et al. (1994b) respectively. It is suggested that one reason for these discrepancies might be that the $\mathrm{HCN}$ measured by Hurst et al. (1994a) and Hurst et al. (1994b) may also have been subject to losses during sample handling and storage. The EF HCN reported here agrees with measurements from other savanna ecosystems (Table 5).

The emission factor for ammonia $\left(\mathrm{EF} \mathrm{NH}_{3}\right)$ lies closest to that reported by Hurst et al. (1994b) for Australian savannas (Table 5), and shows no significant difference from that reported for global savannas in Andreae and Merlet (2001) and Akagi et al. (2011).

\section{Summary and conclusions}

Griffith et al. (1991) first demonstrated the use of long openpath FTIR for vegetation fire emission ratio measurements, and this approach was then revisited by Wooster et al. (2011) where a methodology for deriving biomass burning trace gas emission factors from these long open-path FTIR measurements was developed and applied to fires in the savannahs of Kruger. That work focussed on five key gases retrieved in different parts of the infrared spectral region $\left(900-3100 \mathrm{~cm}^{-1}\right)$. Most recently, Akagi et al. (2014) also deploy a long openpath FTIR methodology at fires in the United States, greatly expanding the number of gases retrieved using this approach. The current work and the companion paper by Paton-Walsh et al. (2014) have retrieved emission factors for 15 different trace gases, has explored different ways of combining timeseries of emission measurements' to derived "whole-fire" emission factors, and has explored relationships between these emission factors and the measurements' modified combustion efficiencies, seasonality and vegetation class. This work has applied these methods to a large number [21] of fires conducted in Australian savanna, including both prescribed/experimental burns and wildfires, and is one of only a few limited studies of biomass burning emissions in the Australian savannas, which is surprising given that Australian savanna burning is an important source of a number of climatologically important atmospheric trace gases at both a national and global level.

Generally, the averaged emission factors presented here are in line with global savanna emission factors (e.g. Akagi et al., 2011; Table 5), with the exception of formaldehyde $\left(\mathrm{H}_{2} \mathrm{CO}\right)$ that has an emission factor of around double of that reported by Andreae and Merlet (2001) and Akagi et al. (2011). This is in line with other studies that deploy open-path methodologies (Paton-Walsh et al., 2010; Wooster et al., 2011). The emission factors for $\mathrm{H}_{2} \mathrm{CO}$ and $\mathrm{HCN}$ are substantially larger than those measured in previous studies of Australian savannas (Hurst et al., 1994a, b). As suggested by Paton-Walsh et al. (2010), who also find discrepancies between their measurements of $\mathrm{H}_{2} \mathrm{CO}$ and $\mathrm{HCN}$ in northern Australia and those of Hurst et al. (1994a, b). One explanation for this underestimation by these earlier studies might be due to losses of $\mathrm{H}_{2} \mathrm{CO}$ and $\mathrm{HCN}$ during sample handling and storage. For $\mathrm{CH}_{3} \mathrm{OH}, \mathrm{CH}_{3} \mathrm{COOH}$, and $\mathrm{HCOOH}$, the emission factors reported here represent one of only a few studies to report EFs of these gases in savanna burning globally and the first for Australian tropical savannas.

The reported variability in emission factors for individual fires (Table 4) and the standard deviation of the mean emission factor calculated from all of the measured fires is large, although it is in line with the variability reported by Akagi et al. (2011). Understanding the causes of this variability is one of the important scientific questions posed by those who wish to better model global biomass burning emissions (van Leeuwen and van der Werf, 2011). Here, and in Meyer et al. (2012), we find that the emission ratios and emission factors varied substantially for different vegetation classes (Fig. 11 and Table 4), but that the MCE of the burns can be used to explain the majority of this variation (Figs. 12 and 13). Data on MCE may soon be available from spaceborne total column measurements as Ross et al. (2013) demonstrate by reporting the first $\mathrm{CH}_{4}$ to $\mathrm{CO}_{2}$ emission ratios measured from space. Given that a significant majority of the variation in the emission factor for trace gases can be explained by MCE, irrespective of vegetation class, we conclude that the selection of emission factors for emissions modelling purposes need not necessarily require detailed fuel type information, if data on MCE (e.g. from such spaceborne measurements) or a correlated variable (e.g. $\mathrm{CH}_{4}$ emission ratios) were available.

The Supplement related to this article is available online at doi:10.5194/acp-14-11335-2014-supplement. 
Acknowledgements. We thank the North Australian Indigenous Land Sea Management Alliance (NAILSMA), Indigenous Rangers of Warrdeken Land Management Limited, the Mok Clan as traditional owners of the field sites. The 2009 Arnhem Land campaigns formed part of a collaborative project supported by the Australian Government Caring For Our Country Program through NAILSMA. We are also grateful for the technical support provided by Bushfires NT and CSIRO. We would like to thank Christopher MacLellan and Alasdair MacArthur of NERC FSF for their wide ranging support, including the loan of the FTIR spectrometer used here. Funding for the studentship of T. E. L. Smith comes from NERC/ESRC Studentship ES/F012551/1. The contribution of Martin Wooster was supported by the NERC National Centre for Earth Observation (NCEO) and NERC grant NE/J010502/1.

Edited by: P. Monks

\section{References}

Akagi, S. K., Yokelson, R. J., Wiedinmyer, C., Alvarado, M. J., Reid, J. S., Karl, T., Crounse, J. D., and Wennberg, P. O.: Emission factors for open and domestic biomass burning for use in atmospheric models, Atmos. Chem. Phys., 11, 4039-4072, doi:10.5194/acp-11-4039-2011, 2011.

Akagi, S. K., Burling, I. R., Mendoza, A., Johnson, T. J., Cameron, M., Griffith, D. W. T., Paton-Walsh, C., Weise, D. R., Reardon, J., and Yokelson, R. J.: Field measurements of trace gases emitted by prescribed fires in southeastern US pine forests using an open-path FTIR system, Atmos. Chem. Phys., 14, 199-215, doi:10.5194/acp-14-199-2014, 2014.

Andreae, M. O. and Merlet, P.: Emission of trace gases and aerosols from biomass burning, Global Biogeochem. Cy., 15, 955-966, 2001

Bertschi, I. T., Yokelson, R. J., Ward, D. E., Christian, T. J., and Hao, W. M.: Trace gas emissions from the production and use of domestic biofuels in Zambia measured by open-path Fourier transform infrared spectroscopy, J. Geophys. Res., 108, 8469, doi:10.1029/2002JD002158, 2003a.

Bertschi , I., Yokelson, R. J., Ward, D. E., Babbitt, R. E., Susott, R. A., Goode, J. G., and Hao, W. M.: Trace gas and particle emissions from fires in large diameter and belowground biomass fuels, J. Geophys. Res., 108, 8472, doi:10.1029/2002JD002100, 2003 b.

Christian, C. S., Stewart, G. A., Noakes, L. C., and Blake, S. T.: General Report on Survey of Katherine-Darwin Region, 1946. Land Research Series No. 1. Commonwealth Scientific and Industrial Research Organization, Australia, Melbourne, 1953.

Cook, G. D. and Meyer, C. P.: Fire, fuels and greenhouse gases, in: Culture, ecology and economy of savanna fire management in Northern Australia: rekindling the Wurrk tradition, edited by: Russell-Smith, J., Whitehead, P., and Cooke, P., 85-164, CSIRO Publishing, Collingwood, Victoria, 2009.

Cook, G. D., Williams, R. J., Stokes, C. J., Hutley, L. B., Ash, A. J., and Richards, A. E.: Managing sources and sinks of greenhouse gases in Australia's rangelands and tropical savannas, Regional Ecology and Management, 63, 137-146, 2010.

DCCEE: Australian national greenhouse accounts: National Inventory Report 2008, Vol. 1, Rep., 279 pp., Department of Cli- mate Change and Energy Efficiency, Commonwealth of Australia, Canberra, 2010.

Garde, M.: The language of fire: seasonality, resources and landscape burning on the Arnhem Land Plateau, in: Culture, ecology and economy of savanna fire management in Northern Australia: rekindling the Wurrk tradition, edited by: Russell-Smith, J., Whitehead, P., and Cooke, P., 85-164, CSIRO Publishing, Collingwood, Victoria, 2009.

Griffith, D. W. T.: Synthetic calibration and quantitative analysis of gas-phase FTIR spectra, Appl. Spectrosc., 50, 59-70, 1996.

Griffith, D. W. T., Mankin, W. G., Coffey, M. T., Ward, D. E., and Riebau, A.: FTIR remote sensing of biomass burning emissions of $\mathrm{CO}_{2}, \mathrm{CO}, \mathrm{CH}_{4}, \mathrm{CH}_{2} \mathrm{O}, \mathrm{NO}, \mathrm{NO}_{2}, \mathrm{NH}_{3}$ and $\mathrm{N}_{2} \mathrm{O}$, in: Global Biomass Burning, edited by: Levine, J. S., The MIT Press, Cambridge, Massachusetts, 230-239, 1991.

Haverd, V., Raupach, M. R., Briggs, P. R., J. G. Canadell., Davis, S. J., Law, R. M., Meyer, C. P., Peters, G. P., Pickett-Heaps, C., and Sherman, B.: The Australian terrestrial carbon budget, Biogeosciences, 10, 851-869, doi:10.5194/bg-10-851-2013, 2013.

Hurst, D. F., Griffith, D. W. T., and Cook, G. D.: Trace gas emissions from biomass burning in tropical Australian savannas, J. Geophys. Res., 99, 16441-16456, 1994a.

Hurst, D. F., Griffith, D. W. T., Carras, J. N., Williams, D. J., and Fraser, P. J.: Measurements of trace gases emitted by Australian savanna fires during the 1990 dry season, J. Atmos. Chem., 18, 33-56, 1994b.

Keane, W. C., Lobert, J. M., Crutzen, P. J., Maben, J. R., Scharffe, D. H., Landmann, T., Hély, C., and Brain, C.: Emissions of major gaseous and particulate species during experimental burns of southern African biomass, J. Geophys. Res., 111, D04301, doi:10.1029/2005JD006319, 2006.

Lobert, J. M. and Warnatz, J.: Emissions from the combustion process in vegetation, in: Fire in the Environment: The Ecological, Atmospheric, and Climatic Importance of Vegetation Fires, edited by: Crutzen, P. J. and Goldammer, J. G., 15-37, John Wiley, New York, 1993.

Lobert, J. M., Scharffe, D. H., Hao, W. M., Kuhlbusch, T. A., Seuwen, R., Warneck, P., and Crutzen, P. J.: (Experimental evaluation of biomass burning emissions: Nitrogen and carbon containing compounds, in: Global Biomass Burning: Atmospheric, Climatic and Biospheric Implications, edited by: Levine, J. S., MIT Press, Cambridge, Massachusetts, 1991.

Lynch, B. T. and Wilson, P. L.: Land systems of Arnhem Land, Rep., 168 pp., Natural Resources Division, Northern Territory Department of Lands, Planning and Environment, Palmerston, 1998.

Meyer, C. P., Cook, G. D., Reisen, F., Smith, T. E. L., Tattaris, M., Russell-Smith, J., Maier, S. W., Yates, C. P., and Wooster, M. J.: Direct measurements of the seasonality of emission factors from savanna fires in northern Australia, J. Geophys. Res., 117, D20305, doi:10.1029/2012JD017671, 2012.

Müller, U., Kurte, R., and Heise, H. M.: Investigation of photometric errors in FTIR-spectra obtained in open-path monitoring, $\mathrm{J}$ Mol. Struct., 482-483, 539-544, 1999.

Parks Australia: Terrestrial Ecoregions in Australia, available at: http://www.environment.gov.au/topics/land/ nrs/science-maps-and-data/australias-bioregions-ibra/ australias-ecoregions (last access: 10 September 2014), 2010 . 
Paton-Walsh, C., Deutscher, N. M., Griffith, D. W. T., Forgan, B. W., Wilson, S. R., Jones, N. B., and Edwards, D. P.: Trace gas emissions from savanna fires in northern Australia, J. Geophys. Res., 115, D16314, doi:10.1029/2009JD013309, 2010.

Paton-Walsh, C., Smith, T. E. L., Young, E. L., Griffith, D. W. T., and Guérette, É.-A.: New emission factors for Australian vegetation fires measured using open-path Fourier transform infrared spectroscopy - Part 1: Methods and Australian temperate forest fires, Atmos. Chem. Phys., 14, 11313-11333, doi:10.5194/acp14-11313-2014, 2014.

Ross, A. N., Wooster, M. J., Boesch, H., and Parker, R.: First satellite measurements of carbon dioxide and methane emission ratios in wildfire plumes, Geophys. Res. Lett., 40, 4098-4102, 2013.

Russell-Smith, J., Yates, C. P., Whitehead, P. J., Smith, R., Craig, R., Allan, G. E., Thackway, R., Frakes, I., Cridland, S., Meyer, C. P., and Gill, A. M.: Bushfires 'down under': patterns and implications of contemporary Australian landscape burning, Int. J. Wildland Fire, 16, 361-377, 2007.

Russell-Smith, J., Murphy, B. P., Meyer, M. C. P., Cook, G. D., Maier, S., Edwards, A. C., Schatz, J., and Brocklehurst, P.: Improving estimates of savanna burning emissions for greenhouse accounting in northern Australia: limitations, challenges, applications, Int. J. Wildland Fire, 18, 1-18, 2009.

Shirai, T., Blake, D. R., Meinardi, S., Rowland, F. S., Russell-Smith, J., Edwards, A., Kondo, Y., Koike, M., Kita, K., Machida, T., Takegawa, N., Nishi, N., Kawakami, S., and Ogawa, T.: Emission estimates of selected volatile organic compounds from tropical savanna burning in northern Australia, J. Geophys. Res., 18, D38406, doi:10.1029/2001JD000841, 2003.

Sinha, P., Hobbs, P. V., Yokelson, R. J., Bertschi, I. T., Blake, D. R., Simpson, I. J., Gao, S., Kirchstetter, T. W., and Novakov, T.: Emissions of trace gases and particles from savanna fires in southern Africa, J. Geophys. Res., 108, 8487, doi:10.1029/2002JD002325, 2003.
Smith, T. E. L., Wooster, M. J., Tattaris, M., and Griffith, D. W. T.: Absolute accuracy and sensitivity analysis of OP-FTIR retrievals of $\mathrm{CO}_{2}, \mathrm{CH}_{4}$ and $\mathrm{CO}$ over concentrations representative of "clean air" and "polluted plumes", Atmos. Meas. Tech., 4, 97 116, doi:10.5194/amt-4-97-2011, 2011.

van der Werf, G. R., Randerson, J. T., Giglio, L., Collatz, G. J., Mu, M., Kasibhatla, P. S., Morton, D. C., DeFries, R. S., Jin, Y., and van Leeuwen, T. T.: Global fire emissions and the contribution of deforestation, savanna, forest, agricultural, and peat fires (19972009), Atmos. Chem. Phys., 10, 11707-11735, doi:10.5194/acp10-11707-2010, 2010.

van Leeuwen, T. T. and van der Werf, G. R.: Spatial and temporal variability in the ratio of trace gases emitted from biomass burning, Atmos. Chem. Phys., 11, 3611-3629, doi:10.5194/acp11-3611-2011, 2011.

Wooster, M. J., Freeborn, P. H., Archibald, S., Oppenheimer, C., Roberts, G. J., Smith, T. E. L., Govender, N., Burton, M., and Palumbo, I.: Field determination of biomass burning emission ratios and factors via open-path FTIR spectroscopy and fire radiative power assessment: headfire, backfire and residual smouldering combustion in African savannahs, Atmos. Chem. Phys., 11, 11591-11615, doi:10.5194/acp-11-11591-2011, 2011.

Yokelson, R. J., Griffith, D. W. T., and Ward, D. E.: Open-path Fourier transform infrared studies of large-scale laboratory fires, J. Geophys. Res., 101, 21067-21080, 1996.

Yokelson, R. J, Bertschi, I. T., Christian, T. J., Hobbs, P. V., Ward, D. E., and Hao, W. M.: Trace gas measurements in nascent, aged, and cloud-processed smoke from african savanna fires by airborne Fourier transform infrared spectroscopy. (A-FTIR), J. Geophys. Res., 108, 8478, doi:10.1029/2002JD002322, 2003. 